\title{
How does meaning emerge on the social level? A dialogic-systems solution
}

\author{
by \\ Michael Urbanski \\ A thesis submitted to \\ the Faculty of Graduate Studies and Research \\ in partial fulfillment of \\ the requirements for the degree of \\ Master of Journalism
}

School of Journalism and Communication

Carleton University

Ottawa, Ontario

August 7, 2007 


$\begin{array}{ll}\begin{array}{l}\text { Library and } \\ \text { Archives Canada }\end{array} & \begin{array}{l}\text { Bibliothèque et } \\ \text { Archives Canada }\end{array} \\ \begin{array}{l}\text { Published Heritage } \\ \text { Branch }\end{array} & \begin{array}{l}\text { Direction du } \\ \text { Patrimoine de l'édition }\end{array} \\ \begin{array}{l}\text { 395 Wellington Street } \\ \text { Ottawa ON K1A ON4 }\end{array} & \begin{array}{l}\text { 395, rue Wellington } \\ \text { Ottawa ON K1A ON4 } \\ \text { Canada }\end{array}\end{array}$

Your file Votre référence ISBN: 978-0-494-33783-7 Our file Notre référence ISBN: 978-0-494-33783-7

NOTICE:

The author has granted a nonexclusive license allowing Library and Archives Canada to reproduce, publish, archive, preserve, conserve, communicate to the public by telecommunication or on the Internet, loan, distribute and sell theses worldwide, for commercial or noncommercial purposes, in microform, paper, electronic and/or any other formats.

The author retains copyright ownership and moral rights in this thesis. Neither the thesis nor substantial extracts from it may be printed or otherwise reproduced without the author's permission.
AVIS:

L'auteur a accordé une licence non exclusive permettant à la Bibliothèque et Archives Canada de reproduire, publier, archiver, sauvegarder, conserver, transmettre au public par télécommunication ou par l'Internet, prêter, distribuer et vendre des thèses partout dans le monde, à des fins commerciales ou autres, sur support microforme, papier, électronique et/ou autres formats.

L'auteur conserve la propriété du droit d'auteur et des droits moraux qui protège cette thèse. $\mathrm{Ni}$ la thèse ni des extraits substantiels de celle-ci ne doivent être imprimés ou autrement reproduits sans son autorisation.
In compliance with the Canadian

Privacy Act some supporting forms may have been removed from this thesis.

While these forms may be included in the document page count, their removal does not represent any loss of content from the thesis.
Conformément à la loi canadienne sur la protection de la vie privée, quelques formulaires secondaires ont été enlevés de cette thèse.

Bien que ces formulaires aient inclus dans la pagination, il n'y aura aucun contenu manquant.

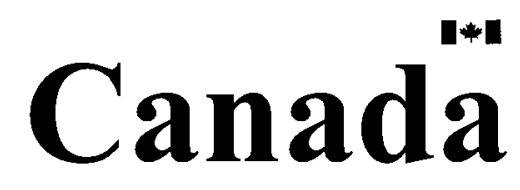




\section{Abstract}

Two schools of thought dominate the inquiry into the nature of meaning construction on the social level: one that sees meaning as practice, and the other as structure. Because the two arise from different intellectual traditions, few attempts have been made to bring the two together.

One of these attempts, put forward by Stephen Ellingson, bridges the gap between structure and practice by positing that there is a dialectical relationship between the two (in which structures change as they are acted out). In this paper, I propose an alternative way of bridging discourse structure and discursive practice - and that alternative is dialogic-systems analysis, which, I argue, offers both a more open-ended and less linear view of meaning-making. 


\section{Introduction: Establishing the paradigm}

1.1 What is social semiotics?

1.1.2 Semiotics vs. social semiotics

1.1.3 Philosophical and methodological value of social semiotics

1.1.4 Shortcoming of social semiotics

1.2 What is systems theory?

1.2.1 Analytic vs. systemic approaches

1.2.2 Systems theory in cultural studies

1.2.3 Middle range systems theory

1.2.4 Conflict Theory vs. Functionalism

\section{Literature review}

2.1 Introduction

2.2 Anne E. Kane: Cultural agency model

2.2.1 Metaphoric nature of meaning

2.2.2 Interpretative nature of meaning construction

2.2.3 Figure: Kane's model

2.3 Mark W. Steinberg: Dialogic analysis model

2.3.1 Dialogic analysis

2.3.2 Discursive field

2.3.3 Figure: Steinberg's model

2.4 Stephen Ellingson: Meaning-event dialectic

2.4.1 Speaker-event-audience relationship

2.4.2 Figure: Ellingson's model

2.5 Three models conclusion

2.6. Systems theory concepts

2.6.1 What is culture?

2.6.2 What is a self-organizing system?

2.6.3 How can culture be seen as a self-organizing complex system

- Emergence

- Autopoietic open system

- Self-organization and change

2.7 Semiotics and systems theory

2.7.1 Peirce's semiotics and systems theory

2.7.2 Emergence and open system

2.7.3 Systems interpretation: Subjective vs. objective 


\section{Dialogic-systems theory}

3.1 Dialogic vs. dialectic

3.2 What is a dialogic system?

3.3 Dialogic-systems theory and power

3.4 Discursive system structure

3.5 Discursive system dynamics

3.6 Multiple discourse dynamics

- The process

\section{Empirical example: Irish Land War}

4.1 Key participants (meaning-makers)

4.2 Symbolic struggle of the Land Movement

4.3 Dialogic-systems theory model for Irish Land War

- Strategies for changing the equilibrium

- Restructuring meanings: Rent and Confiscation

4.5 Conclusion

\section{Future research}

6. Bibliography 


\section{List of tables and illustrations}

\section{Chapter 1}

TABLE 1.1: Comparing traditional analytical modes of investigation with the systems theory approach.

\section{Chapter 2}

FIGURE 2.1: Schematic diagram illustrating the process of new meaning construction as put forward by Kane.

FIGURE 2.2: Schematic diagram illustrating the process of new meaning construction as put forward by Steinberg.

FIGURE 2.3: The triadic relationship between speakers, audiences and events.

FIGURE 2.4: Schematic diagram illustrating the process of new meaning construction as put forward by Steinberg.

FIGURE 2.5: Cultural self organization

FIGURE 2.6: Peirce's triadic relationship of the sign.

FIGURE 2.7: Object as a conditioned variety of $\mathrm{n}$ meanings that is both multidimensional and limited.

\section{Chapter 3}

FIGURE 3.1: Dialectical view of change.

FIGURE 3.2: Dialogic view of change.

FIGURE 3.3: Meaning arises out of the interaction between the system and the environment, retaining the characteristics of both.

FIGURE 3.4: The operation of centrifugal and centripetal forces on discursive system.

FIGURE 3.5: Discursive system levels and hierarchy

FIGURE 3.6: Hierarchies of discursive field scale in complex systems.

FIGURE 3.7: The feedback structure of the discursive system.

FIGURE 3.8: The process of distinct discursive systems coalescing into a discursive field.

FIGURE 3.9: Discursive system equilibrium

\section{Chapter 4}

FIGURE 4.1: Dialogic-systems theory interpretation of the Irish Land War.

FIGURE 4.2: The change in the meaning of "confiscation" as seen through a systems theory lens.

FIGURE 4.3: The change in the meaning of "rent" as seen through a systems theory lens. 


\section{Introduction: Establishing the paradigm}

"All that can fall within the compass of human understanding, being either, first, the nature of things, as they are in themselves, their relations, and their manner of operation: or, secondly, that which man himself ought to do, as a rational and voluntary agent, for the attainment of any end, especially happiness: or, thirdly, the ways and means whereby the knowledge of both the one and the other of these is attained and communicated; I think science may be divided properly into these three sorts." (Locke, 1823/1961:308-9)

In the above quotation, the British philosopher John Locke suggests that there are, very broadly, three areas that are worthwhile of systematic academic pursuit. The first two disciplines are what today we would see as science and ethics, and the third, "the ways and means whereby the knowledge ... is attained and communicated," is addressed, at least in part, by communication studies and, I shall argue, semiotics, which is to say a study of signs and sign systems, and ways in which they are constructed and received.

In this paper, I will look at recent developments in theory-making activities that try to account for how meaning is generated on the social level and how it changes. I will then attempt to bring together dialogism, social semiotics and systems theory - and propose that they can be "fused" together to form a system that incorporates their respective insights.

Thus, in the first section of this paper, I will talk about the origin and current developments in social semiotics and about systems theory in general, which is currently experiencing a sort of academic renaissance - especially in hard sciences, such as biology and ecology, and in cognitive science - having been a more or less a peripheral discipline since its inception in the 1950 s.

In the second section, the literature review section, I will look at three recent models of how meaning arises on the social level, and outline what I see as key insights 
of each of the three frameworks. In the second part of this section, I look at key selforganizing systems theory concepts and broadly discuss their relevance to the study of culture and meaning.

In the third section, I outline a possible self-organizing systems model, which I argue can replace a model outlined by each of the three theorists discussed in section two. I conclude the paper with section five, where I look at the possibilities for future research into the applicability of systems theory thinking to cultural studies and the key contentions that will have to be resolved to successfully develop of a systems-dialogic theory of meaning emergence. 


\subsection{What is semiotics?}

Semiotics has its early roots in linguistics and particularly the work of the Swiss linguist Ferdinand de Saussure, who is considered by many to be the father of modern linguistics. Another early thinker and Saussure's contemporary, the American pragmatist Charles S. Peirce, introduced his own triadic conception of the sign.In general, it can be said that in communication studies today Peirce's conception of the sign (as the relationship between the object, its representation and its meaning) - mainly because of the clear distinction between representation and meaning - is the conception of the sign that most cultural theorists and social scientists favour.

The early efforts in the study of semiotics (Saussure, Peirce, Morris) tried to systematize and establish semiotics as a field of study, giving priority to schematizing ways in which signs and symbols are put together and deployed in communication. Seeing that linguistics was an already well-established discipline at the time, they borrowed many of their concepts from linguistics.

Modern semiotics branched out into a number of areas and heavily influenced both structuralism and post-structuralism. Here the key figures include Ferdinand de Saussure, the French anthropologist Claude Lévi-Strauss, the psychoanalyst Jacques Lacan, the Austrian philosopher Ludwig Wittgenstein, as well as French postmodernists Jacques Derrida, and Michel Foucault. Others whose work has focused on semiotics include literary theorists (Mikhail Bakhtin), feminist cultural theorists (Julia Kristeva) and cultural philosophers (Jean Baudrillard, Umberto Eco).

Structuralists, such as Lévi-Strauss and Lacan, used semiotics to explore how language structures shape our experience of meaning focussing, respectively, on myth 
and the unconscious. The later thinkers, on the other hand (Foucault, Derrida, Kristeva, Orwell), tended to explore semiotics' social implications and applications, and the limits that semiotics sets for social behaviour, including questions surrounding juxtaposition of language, power, society and politics.

Most recently, semiotics has been applied by natural science researchers as well as by social scientists - in particular those interested in studying very complex selforganizing systems. Thus, various semiotic insights have been used to analyze (or reanalyze) evolutionary biology (Stanley Salthe, Stuart Kauffman); non-equilibrium thermodynamics (Ilya Prigogine); cybernetic models of ecosocial interactions (Gregory Bateson); systems ecology (Howard Odum), and animal communication or zoosemiotics (Thomas Sebeok).

While it is safe to say that the role of semiotics in communication studies is central, there is little agreement on what exactly its role in the field as a whole should be - or indeed what kinds of insights can possibly be delivered by this approach to the study of communication. The proponents see social semiotics as a way of studying those areas where any kind of instrumentalization or quantitative analysis is impossible because the subject studied - social meaning of symbols, for example - is too complex. Others see semiotics as a loose collection of interpretative methods characterised by ad hoc methodology and self-indulgent scholastic rhetoric.

But regardless of the debate around the general adequacy of semiotics, it is likely that the discipline will remain an important part of any cultural theory-making activity, if for no other reason than because other approaches are simply unable to transcend their own limitations. 


\subsubsection{Semiotics vs. social semiotics}

"At any given time, in any given place, there will be a set of conditions social, historical, meteorological, physiological - that will insure that a word uttered in that place and at that time will have a meaning different than it would have under any other condition .... as such, it is that which a systematic linguistics must always suppress." (Bakhtin 1981:428)

It is in this sense that social semiotics starts where the more formalized accounts of language - philosophy of language, linguistics, anthropology and even semiotics proper - end. It tries to capture that which necessarily escapes any sort of formalisation the particular. Thus, whereas semiotics proper is focused on providing more formalized accounts of language - abstracting signs from their social context or use to see how they are put together - social semiotics chooses instead to focus on the process of meaningmaking, or, in the words of Peirce, "semiosis".

In other words, contemporary social semiotics has moved away from the structuralist concern with the internal relations of symbolic parts and the general principles of their operation within a self-contained system, and towards exploring the use of signs as social means and indeed as social phenomena in their own right.

\section{Where does meaning come from in social semiotics?}

"What we have in mind is not an abstract linguistic minimum of a common language, in the sense of a system of elementary forms (linguistic symbols) guaranteeing a minimum level of comprehension in practical communication. We are taking languages not as system of abstract grammatical categories, but rather languages as ideologically saturated, language as a world view, even as a concrete opinion, insuring a maximum of mutual understanding in all spheres of ideological life." (Bakhtin 1981:270)

Social semiotic approaches to meaning-making submit that meaning is created in a dynamic social process of meaning negotiation and - depending on the particular 
approach - tend to insist that the two aspects that guide the making of meaning are: social dynamics and power relations, and the structures of language within which the negotiation is taking place.

This is not to suggest that social meaning systems change readily. We know, in fact, that meaning systems can be very difficult to change - even if evidence that refutes their validity is widely available. A case in point is our oblivious attitude - as evidenced through our inaction - to global warming, despite dozens of studies and hundreds of petitions by top scientists calling for immediate action. Nonetheless, social meanings do change and often significantly. And so, as social semioticians, we must ask: How is this possible?

The most general answer in terms of social semiotics is that change in meaning is possible by the virtue of the fact that the relationships between symbols and that to which they refer is metaphoric, which is to say that symbols are multivocal or ever ready to take on a different - and even multiple - meanings. And what the final meaning ends up as depends on: the speakers' and leaders and audiences' discursive goals, interests and understandings; the pre-given language structures within which they can possibly operate; and the particular discursive power relations situation within and among groups.

Thus, meaning-making - or using cultural models or narratives to reinterpret existing symbols - is determined by both: discourse use and discourse structure. This is to say that what something means is determined by both its interaction with other structures of language and its actual or potential social uses. It is in this sense, as Bakhtin (1981) points out, that "the word in language is half someone else's"- we shape language by using it, but we are also shaped by it (acting within pre-given structures). This also 
means that social semiotic analysis must be both social, in that meaning is a function of social interactions, and semiotic, in that the available symbolic structures limit what can be expressed and understood.

\subsubsection{Philosophical and methodological value of social semiotics}

Because social semiotics helps to denaturalize traditional epistemological assumptions and dichotomies (culture/nature, fact/value, theory/method), it raises new theoretical questions. Within this field, the analogy of language as an organism is extended to culture as an organism, and the researcher examines the relationships between communicative practices and structures with an assumption that meaning is embedded in the aforesaid practices. It takes as a unit of analysis an instance/context relationship of language/sign use and structure rather than, for example, using some sort of generalizing principle to uncover hidden structural dynamics (as in, for example, the structural anthropology of Lévi-Strauss).

It differs from the more formalized accounts of language - such as linguistics, philosophy of language, more traditional communication theories and even semiotics proper - in that it insists that meaning is embedded in a series of negotiations over meaning (communicative practices), and that meaning can become apparent through the examination of particular sets (or systems) of those acts (or, as Wittgenstein termed this, language games).

Secondly, social semiotics is valuable as a methodology. I will suggest that systems thinking can adopt semiotics as its methodology - or the modus operandi of its theory-making - and that doing so would be more appropriate to using the more traditional explanatory principle of causality. This is to say that within the social semiotic 
systems framework, the investigator can theorize about the operational and structural dynamics of the self-organizing discursive eco-system rather than trying to delimit and operationalize socio-cultural phenomena, and crunch the numbers to prove relationships between them.

While there are many competing theories of meaning in contemporary communication studies, the central theme - where does meaning come from and how? is either expressly addressed or presupposed by every one of these theories; and more often than not, communications theories lean toward the open-endedness of semioticsbased theories.

\subsubsection{Shortcoming of social semiotics}

While, as I mentioned earlier, social semiotic theories allow us to ask questions that are beyond the scope of other theories, they do not lend themselves very easily to quantification, as other somewhat related approaches (such as content analysis in Frame Theory) do. Thus, at least for the moment, the possibility for empirical testing in social semiotics is limited to ethnographic and phenomenological approaches (Chandler 2007). 


\subsection{What is systems theory?}

"Self-organization is a process where a system reproduces itself with the help of its own logic and components (i.e. the system produces itself based on an internal logic). [The system] can't be reduced to single elements, it is due to the interactions of the system's elements. Hence, a system is more than the sum of its parts." (Fuchs 2007)

Self-organizing systems thinking has been around for a while. In its modern incarnation, systems theory is generally traced back to the 1950 s and the work of the Austrian biologist Ludwig von Bertalanffy and the English psychiatrist William Ross Ashby, who developed the basic concepts in cybernetics (i.e. communication).

At its centre, systems thinking is the idea that behaviour of components of a system is best examined by examining the interactions of the structures of the system and its components rather than the components alone (it is characterized, in other words, by the belief that the whole is greater than its parts). In essence an anti-reductionist analysis, systems theory tries to capture system behaviour as a network of relationships among its elements as well as the environment.

\subsubsection{Analytic vs. systemic approaches}

"This table, while useful in its simplicity, is nevertheless a caricature of reality. The presentation is excessively dualist; it confines thought to an alternative from which it seems difficult to escape. Numerous other points of comparison deserve to be mentioned. Yet without being exhaustive the table has the advantage of effectively opposing the two complementary approaches, one of which - the analytic approach - has been favoured disproportionately in our educational system." (De Rosnay 1979:79, quoted in Principia Cybernetica Web). 


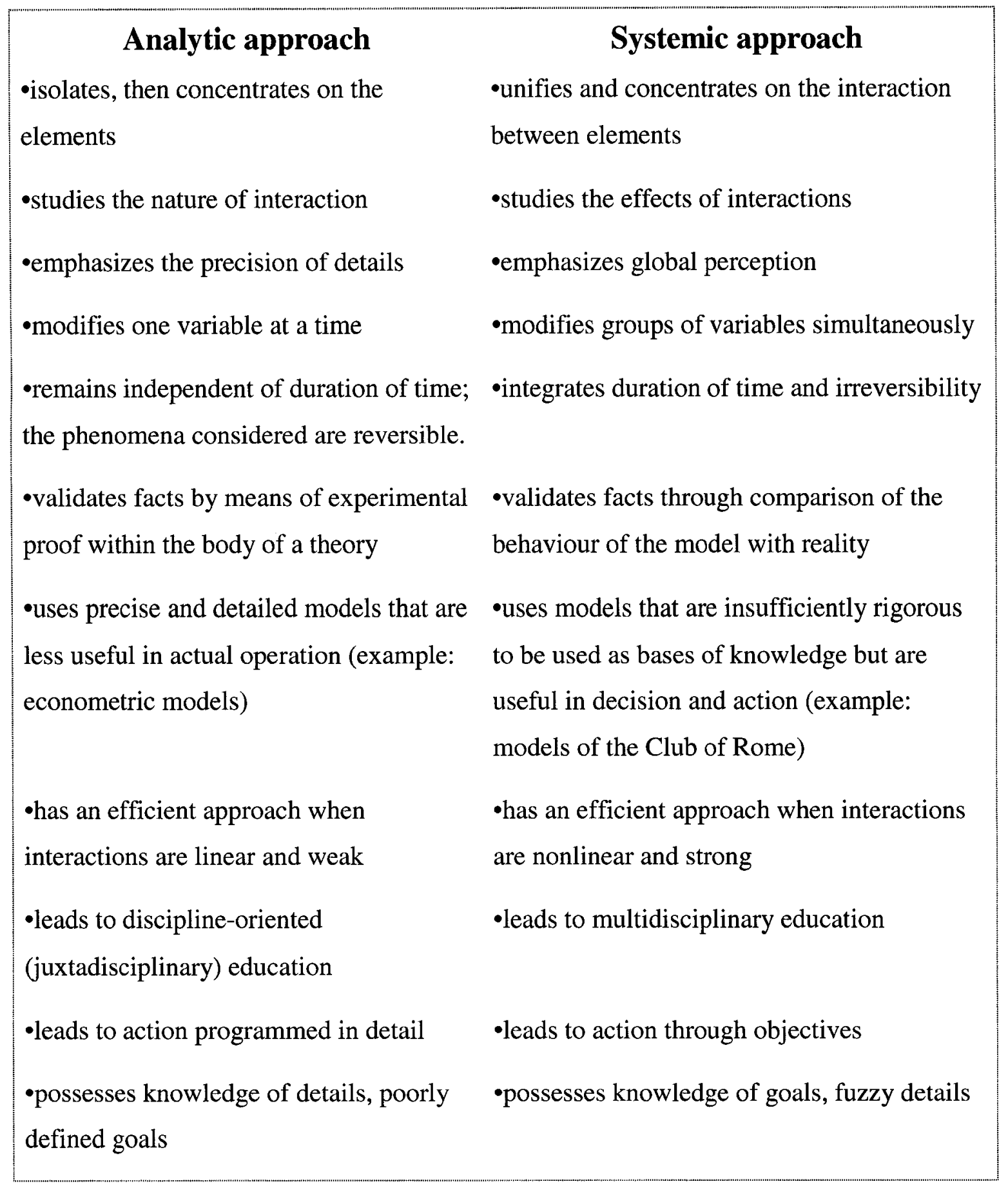

TABLE 1.1: Comparing more traditional analytical modes of investigation with the systems theory approach.

The two approaches - the analytic and the systems approach - are not reducible to each other. That's because they differ in what they consider a worthwhile mode of 
justification as well in what they consider a worthwhile unit for analysis. But they can be said to be complementary in the sense that they both offer us different insights into the phenomenon at hand. 


\subsubsection{Systems theory in cultural studies}

In cultural sociology, the most prominent early self-organizing systems theorist was the functionalist Niklas Luhmann (who wrote in the 1960s, but is still widely popular), for whom social systems are in essence systems of communication - or systems of meaning processing. He characterised systems as autopoietically closed, which is to say that these systems of meaning use only their own internal resources (private and public meaning structures and narratives) to produce meaning. For Luhmann, each system's identity (and thus existence) is dependent on being constantly reproduced in its communication - otherwise the system will no longer preserve its distinct identity against the background environment from which it emerged.

Luhmann was not concerned with people as proprietors of communication, only with communication itself. In other words, he separated the descriptive aspects (which have to do with fact) from the normative aspects (which have to do with value judgements) of communication. This analytical move has since become fairly unpopular among cultural theorists and sociologists of culture, who point out that systems of knowledge (and language) are by their very nature value-laden. (Luhmann's theory has in fact been characterised as anti-humanist by Jürgen Habermas and the postmodernist critics - a comment Luhmann himself considered complimentary.)

I will later argue, however, that this "antihumanism" need not necessarily be true for self-organizing systems theories in general - or at least not to the extent that Luhmann proposes. The result will be a more epistemologically humble system (in that communication will become a much less predictable or tangible activity). But this new 
theory may just be able to integrate systems thinking with the insights of social constructivist theorists.

Indeed, in the later sections of this paper, I will argue that such integration is not only plausible and consistent with key insights of theorists working within other intellectual traditions (discussed in the Literature Review section), but that doing so may result in a very worthwhile and new theory-making tradition.

\subsubsection{Middle range systems theory}

The theoretical approach proposed in this paper is meant to bear the characteristics of what has become known in sociology as the theories of the middle range. The concept was originally developed by the American sociologist Robert K. Merton who was of the opinion that social scientists' true task - partly because of the inherent limitation of social and cultural theories, partly because of the complexity and/or unavailability of the data - is to explain a limited amount of data rather than propose a universal theory of the workings of society (or culture).

Thus middle range theories are theories that are applicable to a limited collection of well delineated data. They are meant to be a solution to the double-sided problem Merton saw in academic theory-making in general: on the one hand heavy reliance on unrefined empiricism (and its realist connotation wherein the world is composed of facts that can simply be collected); and, on the other hand, the all-inclusive, universalizing theories (that have a tendency to account for all aspects of reality - such as Marxism).

In this tradition, theorizing starts by the researcher delimiting the (social, cultural) phenomena with which they will concern themselves, and proposing a model that would represent the workings of the phenomena. So for example, a cultural researcher would 
choose an instance of historical discourse change, document the evidence for this change, and propose an explanatory framework that would explain - and with any luck predict that change.

Merton saw middle range theories as eventually converging "into a system of universal laws on the model of experimental natural sciences," and insisted that, like in natural sciences, theories have to be constructed in constant reference to observable phenomena.

\subsubsection{Conflict Theory vs. Functionalism}

Sociologists have long argued over whether society (and culture) is a result of a collaboration or competition among people or discourses. The functionalist tradition - the tradition with which systems theory is usually associated (e.g. Luhmann) - sees society as an entity composed of inter-dependent components that work together. In this understanding, society is a system wherein social entities (the institutions, the economy, the political system) form a structure which, on the cultural level, defines its participants' roles (functions) in the system and is in turn defined by them.

"The [functionalist] theory is based around a number of key concepts. First, society is viewed as a system - a collection of interdependent parts, with a tendency toward equilibrium. Second, there are functional requirements that must be met in a society for its survival (such as reproduction of the population). Third, phenomena are seen to exist because they serve a function." (Holmwood 2005:87)

Because traditionally systems theory has been associated with functionalism, a number of criticisms (by postmodernists, Marxists and feminists) have been levelled at its capacity to account for phenomena that defy being systematized. For example, Holmwood says theorising meaning construction in term of systems emphasizes 
integration and consensus, while not appreciating independence, conflict and disintegration (Holmwood 2005:99). This anti-functionalist view, called conflict theory, emphasizes that social structures and meanings are a result of conflict rather than, as in functionalism, cooperation among parts or participants.

While historically systems theory emphasis may have been on cooperation rather than conflict (functionalism), the theory of complex systems itself does not necessitate such an interpretation. In fact, conflict and disintegration are a part of the very logic of emergence of new systems. For new systems to emerge, while older systems need to give way, they don't - and I will address this in the next section's discussion of dialogism need to disappear altogether.

For example, in Steinberg's (1995) conception of meaning construction (next section), meaning change is often brought about by speakers who exercise their agency by "kneading" the message to oppose others' meanings (sometimes challenging them, sometimes moulding them, sometimes dismissing them altogether), and are highly responsive to their audiences, who legitimize their messages.

In the next two sections I will argue that the insights of both functionalism and conflict theory can be integrated if a theoretical framework can account for both the conflictual and the cooperative aspects in meaning negotiation, which is to say establish how disintegration and discontinuity are not so much flip sides of integration and continuity but rather prerequisites to the former's identity (in that a discursive system's identity is established by the virtue of both the system's difference from other systems as well as their its own elements). This theoretical move - i.e. replacing the concept of 
polarization with the concept of interaction - is the essence of the difference between dialogism and dialectic - something I will discuss in my thesis section. 


\section{Literature review}

\subsection{Introduction}

This literature review, in its first part, will focus on three fairly recent (1995-1999) papers on the nature of meaning formation in social movements and, by extension, in culture generally. In the second part, I will review and discuss the basic concepts of semiotics and systems theory and their applicability to the study of culture.

These papers represent the current theory-making trends in broadly conceived cultural studies, and promise to inform academic efforts in fields ranging from communication and political studies to cultural sociology and anthropology.

Each of the three papers proposes an analytic framework which, the authors claim, helps us understand how the stuff that makes up culture - discourses, narratives, communicative practices - changes as a result of the interaction among the meaningmakers, which is to say those who have the power to change these social meanings, and thus the culture itself.

The papers I examine are:

- "Theorizing Meaning Construction in Social Movements: Symbolic Structures and Interpretation during the Irish Land War, 1879-1882," by Anne E. Kane;

- "The Talk and Back Talk of Collective Action: A Dialogic Analysis of Repertoires of Discourse among Nineteenth-Century English Cotton Spinners," by Mark Steinberg.

- "Understanding the Dialectic of Discourse and Collective Action: Public Debate and Rioting in Antebellum Cincinnati," Stephen Ellingson. 
Each of the three papers proposes a theoretical model for understanding meaning transformation in culture and uses a particular historical event as an empirical illustration that - and how - the model "works". In the following sections I will highlight the key assertions made by each of the three papers and posit that they can be brought together in a single systems theory model (next chapter).

In the second part of this section, I will show that: (i) the theory of self-organizing complex systems is consistent with the key assumptions and insights of the three theorists discussed in the Literature Review section; and (ii) the theory of self-organizing complex systems has the capacity to bring these insights together under a single framework, and that doing so is worthwhile. I will also talk about how Peirce's semiotics can be seen as methodological basis for a dialogic-systems theory.

\section{Three models of social meaning construction: Kane, Steinberg, Ellingson}

The essential task of Kane, Steinberg and Ellingson is to propose a theoretical explanation (model) for how meaning is constructed and cultural systems transformed in historical events. They all posit - in one way or another - that any worthwhile studies of social meaning construction must integrate the analysis of the logic of symbolic meaning systems and studies of social movements to understand the object of their study.

Generally, then, Kane posits the autonomy of culture in making social meaning, and in particular the key role of culture in the course and outcomes of social movements, focussing on how the dominant discourse coalesces into being from fragmented constitutive discourses.

Steinberg, on the other hand, with his detailed outline of the nature of the discursive field, explores the conflict-ridden cultural terrain and focuses on the 
production of meaning as contested collective action, where meaning is created by conflict and is therefore unstable.

The third theorist, Ellingson, analyses how the negotiation of meaning inside the discursive field changes both the meaning and the structures of the discursive field (that determine the meaning), and how speakers adjust their messages and set up discursive alliances to ensure public support for their arguments.

Thus from Kane's model, I appropriated the focus on the symbolic fusion of meaning; from Steinberg's model, its comprehensive layout of the structures of the discursive field; and from Ellingson's model the dialectical nature of the processes of meaning negotiation and emergence. I will now have a closer look at each of these models.

\subsection{Anne E. Kane: Cultural agency model}

Generally, Kane posits that "examining the metaphoric condition of symbols and the interpretive mechanism of people using these symbolic systems in concrete situations should precede and then continue concomitantly with the examination of public symbols, practices and power in social movements." (Kane 1997:243)

More specifically, Kane asserts that incorporating the metaphoric basis of meaning and the interpretive mechanism of meaning construction will enable social movement analysts to fully attend to the cultural preconditions of activism, how political consciousness and ideology derives from interaction between individuals, how movement participants navigate sociocultural processes and contested meanings, and what really happens in sites of social interaction where meaning is constructed. 


\section{Metaphoric nature of meaning}

Kane's first theoretical assertion is that "the locus of meaning is symbolic structures" of culture. This view - often called "culture as structure" perspective - runs contrary to the "culture as practice" perspective discussed in the introduction, wherein meaning is the participants' interaction with the cultural structures within which they operate. Kane's "cultural agency" model agrees that agents make meanings as they enact them, but posits that it's more worthwhile to examine the structures within which they operate.

In other words, Kane argues - and in my own model I will agree - that meaning construction takes place within the context of the semiotic logic of symbolic (cultural) systems that serve as a frame of reference to those involved in meaning production.

For Kane, symbols - which are building blocks of cultural systems - operate as metaphors, which is to say symbols operate in relationship to other symbols in a system and "strongly but ambiguously signify social relationships, conditions and experiences through associations of similarity and difference between separate entities." (Kane 1997:250). And symbols' power to affect action lies in their particular relationship to other symbols in a symbolic system/structure and in how people interpret them.

Importantly, however, Kane is not "claiming a causal priority of semiotic systems over human agency, contingent events, or structural conditions, but that people refer first to cultural models as they try to make sense of situations and shape their strategies for action." (Kane 1997:250) This is to say that people interpret experience in relation to their symbolic template - and thus Kane's second theoretical assertion. 
Interpretative mechanism of meaning construction

"Because meaning is embodied in the specific arrangement of symbols in cultural models, and cultural models are the first point of reference when people interpret experience, these structures should be the initial theoretical and analytic focus in studying meaning construction." (Kane 1995:251)

According to Kane, all movement participants engage in interpretation of symbolic systems to construct meaning and plan action. Furthermore - contrary to the theoretical contentions of frame theory - discursive interaction becomes contentious when symbolic understandings and expression collide, but does not necessarily end in one meaning prevailing over another. Instead, discursive contention usually resolves through symbolic fusion and combination and produces an emergent "new" meaning that is a combination of the constitutive meanings. Because meaning construction and reconstruction is based on collective interpretation, what results from this process is highly contingent and thus unpredictable, or emergent.

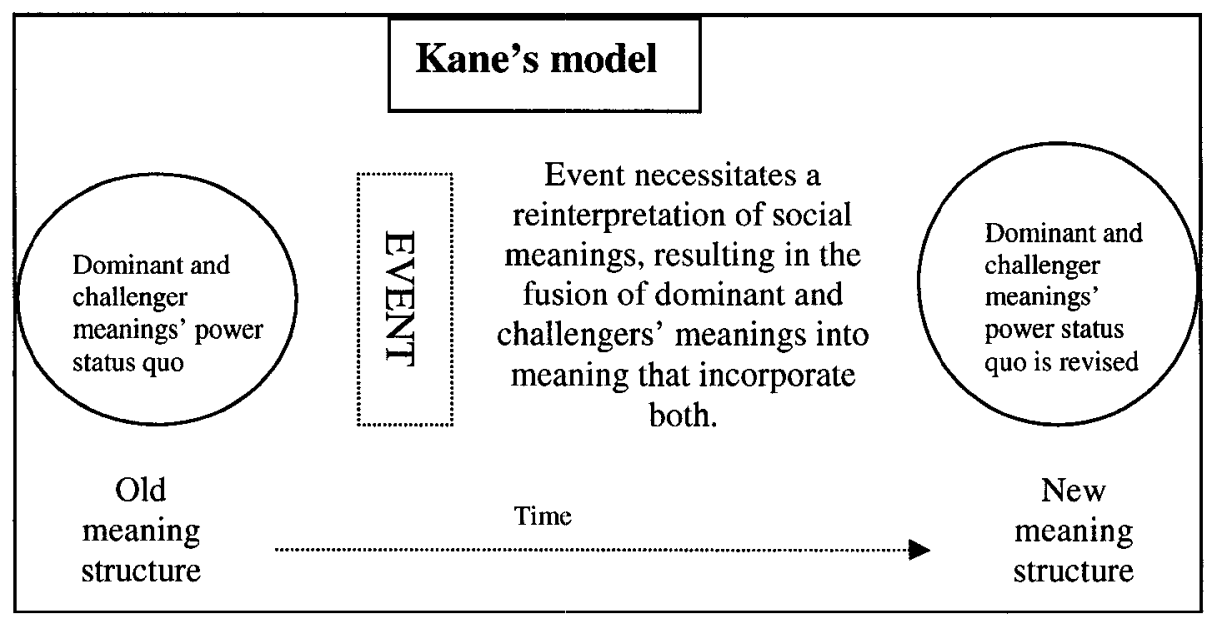

FIGURE 2.1: This schematic diagram illustrates the process of new meaning construction as put forward by Kane. 


\subsection{Mark W. Steinberg: Dialogic analysis model}

"Rather than assuming communication as the sending and receiving of messages whose meanings are evident and unproblematic, [dialogism] offers a model of discourse as a dynamic, conflict-ridden cultural terrain." (Steinberg 1999:748)

Steinberg's paper criticizes framing perspectives on social movement meaning construction and offers an alternative "dialogic" approach. He posits that his dialogic approach sees social discourse as a product of movement participants' agency and discourse dynamics (the latter, in Steinberg's definition, resemble Kane's in that Steinberg agrees that meaning is both multivocal and relational).

Also like Kane, Steinberg sees the production of meaning as contested collective action, where meaning is created by conflict and is therefore unstable. He sees discourse as a joint product of challengers' rational actions and the constraints of the discursive field. Challengers seek to appropriate and subvert the dominant discourses that legitimate power, in the process creating discursive repertoires.

\section{Dialogic analysis}

"Frame analysis valuably focuses our attention on processes of ideological and cultural production for mobililzation and action but undertheorizes the semiotic aspects of framing. A dialogic perspective furthers our analyses of discourse dynamics, particularly in terms of its multivocality and the semiotic processes that underlie it." (Steinberg 1999:744)

Indeed, dialogism, a term originally proposed by the Russian literary theorist

Mikhail Bakhtin, sees discourse as an ongoing process of social communication, where meaning is partly a product of social interaction and partly a product of how streams of language themselves interact.

Following many post-structuralist insights, Steinberg sees language as inherently political and ideological. This is to say that struggles over meaning are in essence 
ideological/political struggles over who gets to determine meaning. Indeed, Steinberg believes that ideology does not exist "outside or prior to discourse but is created and structured in and through ongoing communication." (Steinberg 1999:745).

This is an idea that Steinberg adopts (following Foucault and Bakhtin), further positing that the analysis of how meaning arises on the social level must be both social and semiotic:

"social in that meaning is a function of the social interactions between people and the contexts in which these take place; and semiotic in that the languages themselves that people use and that are available to them to express their senses of the world limit what can be expressed and understood." (Bakhtin 1986: 65-71, quoted in Steinberg).

Adopting this view of meaning (it diverges from the framing theory understanding of meaning in that it acknowledges and provides for the semiotic aspect of meaning making) allows Steinberg to conceptualize both meaning and the discursive field as negotiable and constantly negotiated in the clash among powerholders (those with the power to determine meanings) and challengers (those who want to delegitimate the language of the powerholders).

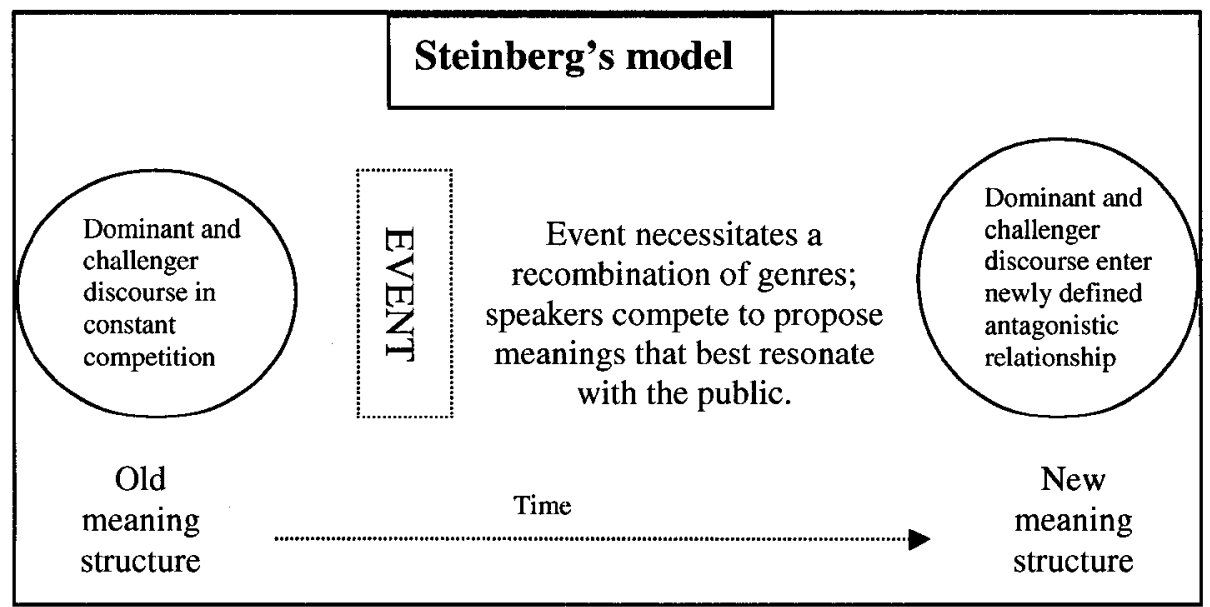

FIGURE 2.2: This schematic diagram illustrates the process of new meaning construction as put forward by Steinberg. 


\section{Discursive field}

"The construction of fields thus involves mutually recognized ... cultural assumptions as to how and when a genre can be applied to a social situation, the extent to which it can relate to other genres, institutional rules for its use and the relations between actors themselves." (Steinberg 1999:748)

The concept of discursive field is somewhat similar to the concept of master frame in Frame Theory (both try to account for enduring discourses and the nature of contention among struggles), but the former is much more dynamic in that it accounts for the fact that meaning is interpreted by actors (the point Kane also makes) and in that discursive field is relational - its contents (speech genres, narratives) arise in relation to others.

Indeed, positing the existence of a discursive field is a way of addressing the fact that social movement participants cannot simply pick and choose meanings (they - as everyone - are bound by a larger cultural structure which is a prerequisite for meaning). Thus, discursive fields become "places" that "contain and construct" diagnoses and prognoses to social problems, and are the limits within which cultural action can take place as well as tools for enacting change.

Discursive field is a set of contextually related genres for structuring meaning, which is to say rules in accordance with which meaning gets made. Meaning conflicts arise over how to combine these genres, but the structure of the discursive field limits the possible combinations (and thus meanings).

On the level of power relations, the discursive field is characterised by a conflictual interaction between powerholders (who already have both institutional bases 
and social standing) and challengers, who have neither - and thus more often than not lack capacity to legitimate their oppositional meanings.

Within Steinberg's vision of the discursive filed, the dominant discursive repertoire is dominated by the powerholders, who strive to impose authority in such a way so as to make the negotiated outcome (i.e. the resulting social meanings or order) appear as the only reasonable solution.

The challengers have their own discursive repertoires (or ways/logics of talking about the world). The challengers, according to Steinberg, want to either undermine the powerholders' repertoires (by showing them to be false - i.e. inconsistent with the facts or internally contradictory, or not good enough in relation to wider social goals) or appropriate them by injecting the challengers' meanings. 


\subsection{Stephen Ellingson: Meaning as meaning-event dialectic}

"Events may change the underlying ideas or beliefs that make up the discourses and frames used by movement actors, resignify which set of collective beliefs are salient, and alter the meaning of actors' interests - all of which affect the power of a particular discourse or frame. (Ellingson 1995:136).

Steinberg's idea of discursive field is further enriched in Stephen Ellingson's analysis of how the negotiation of meaning inside the discursive field and its interaction with real-world events changes both the negotiated meaning as well as the structures of the field.

Ellingson attempts to address how events influence meaning construction and how the resulting new meanings alter existing meaning structures. As for Steinberg, for Ellingson discursive fields are primary sites of contention over meaning. They are places where competing movement speakers "battle over which poles will govern debate because control over them endows some speakers with the power to set agendas and guide the direction and content of debate." (Ellingson 1995:108)

According to Ellingson, some of the strategies used by speakers can include: shifting the definition of the situation from a specific or practical level to a more general or conceptual level; changing the focus of a discourse to render it more resonant with the audience or to gain entry into a debate (environmentalists in Canada, for example, rarely use moral arguments when talking to the politicians, preferring instead to emphasize practical benefits of adopting their discourse); aligning their discourse with already legitimized institutional discourses.

These struggles to control the discursive field take place at the level of concrete arguments. These arguments are at once proposed solutions to the problem they address and emissaries of their parent ideologies. With every new development (say a passing of 
a bill in Parliament) speakers adjust their discourses by framing new problems and setting up new discursive alliances to ensure support for their positions.

Meaning here - as for both Steinberg and Kane, but here more explicitly - is an outcome of an ongoing contestation among speakers in a discursive field, who seek to solidify their positions by redefining and otherwise recasting issues (as per the strategies above). But for Ellingson there is another side to this. Just as meaning is in part an outcome of the interaction among speakers, it is also an outcome of the speakers' interaction with the audience and their actions, which themselves are influenced by the debate.

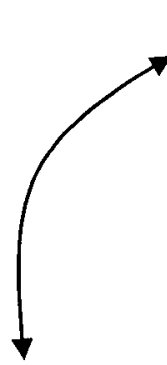

Event

Audience
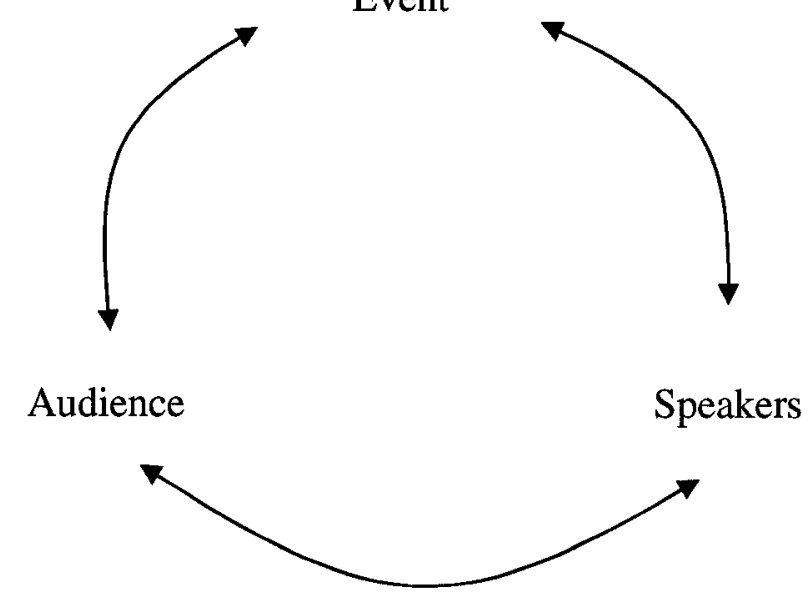

FIGURE 2.3: The triadic relationship between speakers, audiences and events.

In this view both speakers and audience engage in the interpretation of events, and as a result the events change their cultural understandings of the world around them. In other words, making meaning impacts the actions of participants, and collective actions impact the making of meaning by "testing" the fit of the arguments and underlying ideologies. This process of dialectic tension between speakers and participants and 
between action and meaning changes both the social and the cultural context of meaning production - and thus the meaning (structure) itself.

Thus by reconceptualizing the relationship among speakers and between speakers and audiences, Ellingson illustrated how actors within the discursive field use events to reconfigure relations within the field. This, in turn, alters a "group's legitimacy, base of support, and power to sanction or prevent further collective action." (Ellingson 1995:136) Ellingson's model also shows that looking into the relationship between events and discourse production can help us understand how and why structures of meaning (as defined by Kane, for example) change.

Finally, Ellingson's model suggests - which of course is confirmed by experience - that different speakers in the discursive field construct their arguments in very different ways. Challengers, for example, "may be more willing to extend and transform their discourses in order to win a place in the debate, influence the agenda, and even force the sponsors of a legitimating frame to defend its underlying assumptions." (Ellingson 1995:137)

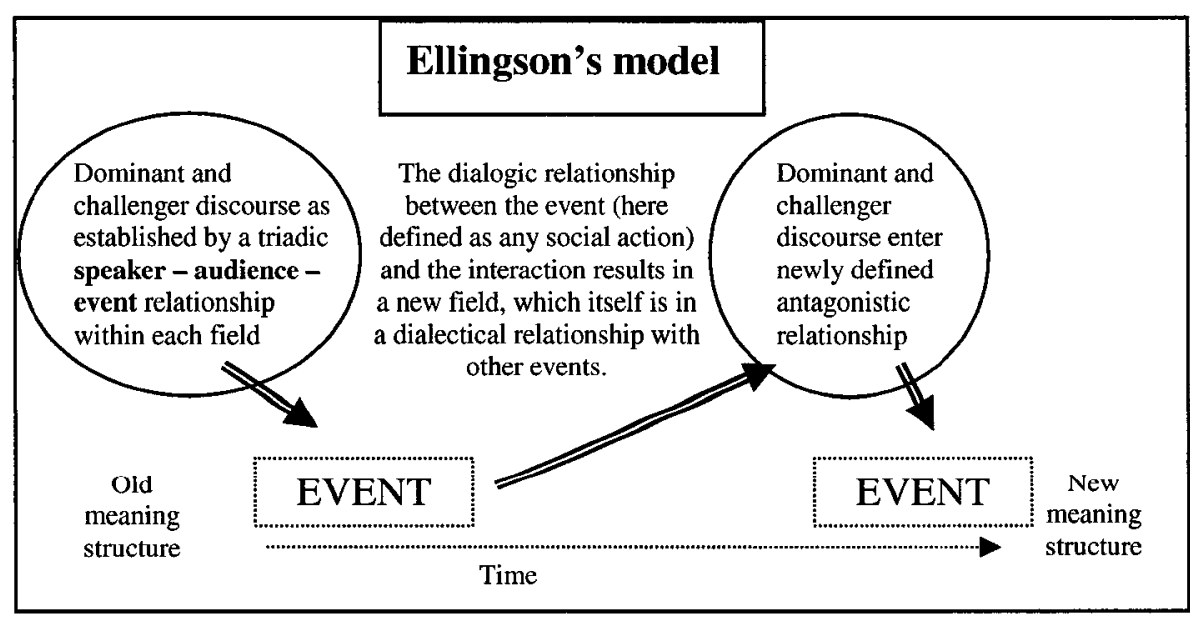

FIGURE 2.4: This schematic diagram illustrates the process of new meaning construction as put forward by Steinberg. 


\subsection{Conclusion}

In one way or another each of the three studies asserts that changes to discursive fields - discursive fields here being a "series of claims, images, or tropes combined in a coherent manner and intended to persuade an audience through an appeal to logic, fact, belief, emotion, or external authority" (Thompson in Ellingson 1995:134) - can best be accounted for by looking at how and why arguments are constructed and reconstructed in the context of the relationship among speakers and audiences, the symbolic structures (which is to say their meaning-making apparatus) within which they operate, and the events that necessitate the change in discourse.

In the next section, I will argue that these three perspectives on meaning construction can be incorporated into a dialogic systems theory model. In the remainder of this section, I will talk about key concepts in the theory of complex self-organizing systems and about how the theory of self-organizing complex systems can be used to study culture and social movements as carriers of culture. 


\subsection{Systems theory concepts}

The task in this section is fourfold: to answer (i) what is culture? (ii) what is a self-organizing system (iii) how can culture be seen as a self-organizing complex system? (iv) how is this self-organizing system applicable to the study of social movements?

\subsubsection{What is culture?}

To answer the first question, culture, in cultural theory, could be defined as systems of meaning embodied in symbols, which (the symbols) allow people to understand their experience of the world and act upon this understanding (Geertz 1973). Culture is also a forum on which subjective cultural artefacts (personal values, narratives and norms) and shared or objective cultural artefacts generate symbolic social structure that allows for and constrains social practices. Or, in the words of Giddens (1979:153), "structural properties of social systems are both the medium and the outcome of the practices that constitute those systems".

It should perhaps be pointed out that culture is a specific symbolic system or structure rather than a totality of symbolic patters of a social group. That's because, as Fuchs (2004:19) explains:

"The difference between cultural structures ... and other social realities is that the first are a direct objectification of creative mental processes. Non-cultural social realities [politics, economics] are not directly cultural realities; they acquire a cultural character when they enter the process of social signification, i.e. when they are related to the realm of world-views, norms, values, morals, ideology and ethics."

In other words, to avoid confusing culture as the only system of knowledge in society - there are other knowledge systems in society (politics, economics, science), which have their own rules and logics of operation - when we talk about culture, we must 
limit our inquiry to a particular culture. (I will return to this in my discussion of the discursive field.)

Culture as structure vs. culture as practice

Two schools of thought dominate the inquiry into the nature of meaning construction on the social level: one that reduces meaning to practice (e.g. Wittgenstein and the idea of language games; Deleuze), and the other to structure (most structuralists, like Kane). While the proponents of either approach usually acknowledge the need to somehow bridge the gap between the two schools of thought, they disagree about how this can or should be done. One thing they do seem to agree on, however, is that:

"Culturally informed sociological analysis is not advanced by the explication of essential meaning structures, but by a more subtle analysis of meaning construction through action. [italics added] Rather than relying on a binary meaning structure to help us understand the various cultural worlds in which we live, we need a conception of meaning-making as the outcome of multiple and contingent processes." (Battani, Hall, Powers 1997:783)

This paper argues that a theory of meaning construction based on the integration of the theory of self-organizing systems with dialogism - with semiotic analysis as its analytical methodology - is one way of bridging the dichotomy that has characterised past analyses of meaning and meaning-making. 


\subsubsection{What is a self-organizing system?}

"A system is a zone of dialogical contact where an organization can be defined as a system of languages that mutually and ideologically interanimated each other...A dialogic system is an opposition of multiple philosophical views, not a monological synthesis." (Boje and Al Arkoubi 2005:59)

Indeed, according to Wikipedia, a system is any set (group) of interdependent or temporally interacting parts. Parts are generally systems themselves and are composed of other parts. A system is characterised by:

- "A dynamic and complex whole, interacting as a structured functional unit

- Inormation flows between the differetn elements that compose the system

- A system is a community situated within an environment

- Information flows from and to the surrounding environment via semi-permeable membranes or boundaries

- Systems are often composed of entities seeking equilibrium but can exhibit oscillating, chaotic or exponential growth or decay." (Wikipedia)

In the following pages, I show how culture can be seen as such a system.

\subsubsection{How can culture be seen as a self organizing system?}

The figure below shows how humans, as agents whose ability to understand and act is limited by (subjective and objective) symbolic structures, take part in creating the very structures that allow us to understand ourselves. 


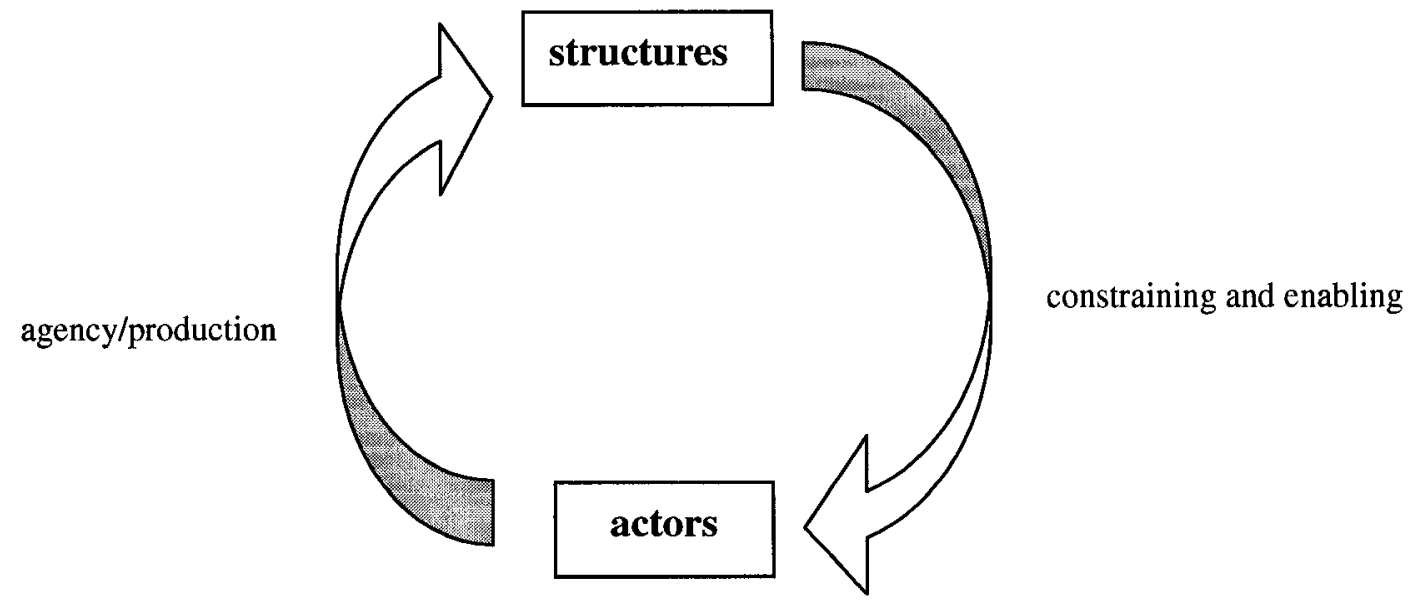

FIGURE 2.5: Cultural self organization (Fuchs 2004:10)

This cultural self-organization is mirrored by the theory of self-organizing complex systems, which posits that the relationship between cause and effect (here actors and structure) is non-linear, which is to say that a cause can result in many effects as well as each effect is a combination of many different causes.

Within this model, system structures (structures of language, for example) interact with events and actors in the process creating a system that is both guided (rather than determined) by its constitutive parts, but which always - both because of the metaphoric nature of language (which allows it to acquire different meanings) and actors' agency features an element of unpredictability.

I will now look more closely at some key concepts in the complex self-organizing systems theory - emergence, autopoietic open system, self-organization and change - and examine their applicability to the study of culture and cultural movements. 


\section{Emergence}

Applying systems theory thinking to the emergence of meaning in culture and social movements allows us to posit that there is no one social element that necessitates the emergence of a particular meaning. In fact, because the relationship between the causes and effects in the social creation of meaning is so complex, it would be more appropriate to talk about the new meaning having emerged rather than having been determined.

Thus, in this view, because there is no single condition that can explain (well enough to be able to predict) the emergence of meaning in social movements, meaning is considered emergent, which is to say it arises through a countless number of of relatively simple interactions.

In his 1999 book, Emergence as a Construct: History and Issues, Jeffrey Goldstein defines emergence as "the arising of novel and coherent structures, patterns and properties during the process of self-organization in complex systems." (pg. 7)

According to Goldstein, the common characteristics of emergence are: (1) radical novelty (features not previously observed in systems); (2) coherence or correlation (meaning integrated wholes that maintain themselves over some period of time); (3) global or macro "level" (i.e. there is some property of "wholeness"); (4) it is the product of a dynamical process (it evolves); and (5) it is "ostensive" - it can be perceived. (Corning 2002:49)

I assert that, generally, socio-cultural movements not so much meet these criteria of emergence (as I explained in the previous chapter, systems models as more about modeling than reflecting reality), but that models made in this tradition can reflect the 
characteristics of emergence. For one, the models exemplify "radical novelty" if simply by the virtue of emerging as a distinct discursive practice/system. They are also coherent in that they are "about something" (Greenpeace "is about" the environement) and, clearly, they "maintain themselves over time". Most movements also have the property of "wholeness", which, according to Ellingson (1995), is a result of 'the principle of differenciation' - a principle that states that for a social movement (or discourse) to acquire identity of its own it needs to place itself in opposition to (in the sense of apart from rather than the strict structuralist sense of opposition) other discourses. (This is why political challengers will almost always take a position that's opposed to the dominant discourse.)

Finally, to address Goldstein's last two criteria, it has been well documented that social movements perceptively evolve and adapt to the ever-changing external sociocultural environment. This, for example, is examined in some detail in Stephen Dale's McLuhan's Children: The Greenpeace Message and the Media, where the author looks at Greenpeace's changing public relations strategy as it adapts, over the years, to its evolving socio-cultural environment.

In the next section, I will look more closely at compatibility of the theory of selforganizing systems with cultural studies and in particular semiotics.

\section{Autopoietic open system}

Another fundamental systems theory idea is that of an open system. An open system is a system that is permeable to outside artefacts (in thermodynamics, it's mass and energy; in cultural studies, it would be outside symbolic structures or narratives), while at the same time retaining its distinctiveness. 
Clearly related to the idea of emergence (in that while emergence highlights indeterminacy of the system, openness highlights the reasons for this), the idea of open system suggests an entity that is self-referential and self-perpetuating yet open to the outside information and indeed reflexive.

A term that best captures this characteristic of open systems is autopoietic - selfcreating. Coined by Chilean biologists Humberto Maturana and Francisco Varela in 1973, it was defined as:

"An autopoietic machine is a machine organized (defined as a unity) as a network of processes of production (transformation and destruction) of components which: (i) through their interactions and transformations continuously regenerate and realize the network of processes (relations) that produced them; and (ii) constitute it (the machine) as a concrete unity in space in which they (the components) exist." (Varela, Maturana, Uribe, 1980)

While social movements are not machines, this biology-based definition of how a system can self-reproduce can and has been "translated" into cultural realities by replacing, as Luhmann has done for example, biological systems with systems of meaning production.

Thus any autopoietic machine (for example the environmental movement) and its "processes of production of components" (the process of discourse production) can be said to be aimed at both sustaining the relations of power that characterise the system which generated these components (discourses) and regenerating themselves in both material and symbolic ways.

As an analogy, if we take the environmental movement as a machine, it is an autopoietic, self-creating machine in that its components (on the cultural level of genres and narratives; on the material level individuals) continuously try to strengthen the inter- 
movement contingencies that produced it. In other words, its messages are put together not just with messaging but self-preservation of the existing movement structure in mind.

This also addresses the second requirement: The fact that discursive systems not only regenerate the cultural system, but are the system in that the structures of the discourse are a part of the system's identity. Thus, as cultural meaning system constructs a view of the world and acts on this construction, an autopoetic system both contains and constitutes "a representation of society within society." (Luhmann 1987:101)

Identifying social movements' cultures with open system allows us to see these movements as using cultural resources available to them internally as well as those external to the system to establish their identities, structures and practices. This, I believe, accurately reflects what in fact happens when social movements identify, communicate and enact their roles on the socio-cultural scene.

To sum up, I think the concept of open system is well suited to describing the operations of social movements because these movements are both somewhat autonomous (in that their systemic identity stands apart from other systems against which it defines itself), and somewhat determined, in that they are connected to social grievances and react to other movements.

\section{Discursive field as a self-organizing entity}

According to Steinberg, discursive fields are "places" that "contain and construct" diagnoses and prognoses to social problems, and are the limits within which cultural action can take place as well as tools for that action. As such, they are sets of contextually related discursive genres that are used by speakers (and audiences) to decode and structure meaning. 
Conflict, according to Steinberg, arises when there is disagreement over how to combine these genres. But the possibilities for this combination (and thus for new meanings), are limited by the structure of the discursive field. The outcome of the conflict, while in the end unpredictable (because of the number of factors), plays itself out between those who currently control the discursive field (and thus the rules that govern it), and the challengers who want to undermine the powerhoders by means of presenting a version of reality that better resonates with the audience.

In fact, discursive field as a systems theory entity can be seen, by way of an analogy, as a battlefield of sorts. At the disposal of each of the warring parties (speakers attempting to win over support for their ideas) in the battlefield (discursive field) are systems of weapons and techniques (genres, repertoires), which can be combined in any manner that's suitable for whatever purpose at a particular time, within the bounds of the weapons' capacity - defined as an outcome of their intrinsic capacity (or available language structures) in relation to the geography of the battlefield (socio-political context) and the opponents' own weapons (genres).

The resulting combination - a particular system of genres - is thus a result of the speakers' ability to combine his resources in such a manner so as to enable himself to represent the issue in question in the most convincing manner. His success is thus due to aspects internal to the system - and thus both propelled and limited by it - rather than extraneous resources. This idea that discourses are an outcome speakers' effort to recombine existing discourses to appeal to the public is clear in the following passage by Steinberg: 
"Contentious discourses are structured not so much by independent grammars of meaning, issue cultures, or some system of beliefs exterior to conflict; rather, they are determined by the ways challengers can combine genres." (Steinberg 1995:750)

Because many combinations of genres (systems of meaning) are possible - and more importantly because they are "tested" in relation to the social situation and adjusted as strategically required (other systems) - the outcome of the contestation is often unpredictable. As we already know, within the logic of systems theory this is called emergence.

\section{Self-organization and change}

Complex self-organizing systems are self-organized in the sense that out of a perpetual struggle and differentiation of actors and ideas there arises a common denominator of sorts that allows us to call the movement a movement. In the next section, I will elaborate on the competitive nature of that struggle as embodied by Conflict Theory. For now, I will addresss the following issue: If cultural systems are so different (in that they have different rules and logics of operation), how is orderly interaction among them possible?

I think we must be careful here not to suggest that meaning is more volatile than we know it to be - we know, for example, that social meanings can be very difficult to change even if evidence that refutes their validity is widely available (global warming). Social meanings do change, however, and often significantly. So as researchers, we must ask: how is this possible?

The answer, in terms of dialogic-systems analysis, is that this is possible by virtue of the fact that the relationship between symbol and object is metaphoric and thus 
multivocal (or open to taking on other and often multiple meanings). What the negotiated meaning ends up as depends on the speakers' or audiences' discursive goals, interests and understandings, the particular situation and power relations within and among groups.

This leads to another characteristic of social meaning change as seen through dialogic systems analysis: meaning interpretation and negotiation is both individual and collective. This is to say that both individuals (on their own) and groups partake in the making of meanings using cultural models or narratives to reinterpret existing symbols so they can accommodate the new situation, and doing so changes the models or narratives themselves.

In this way, semiotics-based systems theory has an advantage over frame theory in that unlike the latter, it allows for changes of meaning within any one frame over time (or between two sub-systems of people in a frame), while at the same time seeing meaning changes as being bound by context. This is to say that as tools frames are not sensitive or equipped enough to account for changes within a frame (even if they may do a reasonably good job in explaining how, in the language of systems theory, frames respond to the environment).

In the systems theory framework, then, meaning is determined by both: discourse use and structure. This is to say that what something means is determined by both its interaction with other structures of language and its social use. It is in this sense that "the word in language is half someone else's," as Bakhtin (1981:294) points out - meaning that we shape language by using it, but we are also acting within pre-given structures. This also means that systems analysis is both a social analysis, in that meaning is a 
function of social interactions, and a semiotic analysis, in that the limits of (broadly conceived) language limit what can be expressed and understood.

It is important to keep in mind that systems theory is not structuralism. Structures, in systems theory, do not reflect the structures of the world or the structures of consciousness but the structures of communication, which change as the communication progresses. In other words, social narratives' structures link and legitimate social institutions, and as the structures of meaning change so do the institutions.

An example of this would be how the symbolic structures of the public spherethat include the narratives of justice and democracy - give authority to the judicial system; had that not been the case, we would have no reason (no frame of reference in which) to feel that we deserve that parking ticket, or that we owe tax, or that it's not really okay to be in contempt of court.

Thus, following Fuchs (2005:123), I suggest that there are a number of advantages to seeing communication as an interaction between self-organizing systems. These include:

- Self-organizing theories would tend to, better than the labour movement, confront non-material issues such as peace, gender, democracy, nature, race, human rights.

- Self-organizing theories have "decentralized, self-organizing, networked forms of organization that are different from the centralistic forms of organization of traditional unions and left-wing parties of the working class."

- Self-organizing theories better account for the fact that many new social movements do not have "strict rules of membership, but fuzzy borders [where] participation replaces membership." 
Systems as models of the interaction of the observer and reality

It is perhaps important to stress at this point that self-organizing systems are a way of observing reality rather than a representation of reality; a way of modeling systems not systems themselves. Because of this, the role of the observer - including the purpose and scope of the observation - all play a role in the content of what is being observed.

"What under some circumstances can be seen as organization, under others can be seen as disorder, depending on the purpose of the system. When ice cream is taken from a freezer, and put at room temperature, we can say that the ice cream disorganizes, since it loses its purpose of having an icy consistency. But from a physical point of view, it becomes more ordered by achieving equilibrium with the room, as it had done with the freezer. Again, the purpose of the system is not an objective property of the system, but something set by an observer."

(Gershenson and Heylighen 2003:609)

This does not mean that self-organizing systems are imposed on reality by the observer and do not exist independently of him. Indeed, there must be (some sort of) a necessary relationship between the world and the observation, otherwise observations would become little more than the mind's fabrications. But the observer is always implicated in what is being observed simply by the fact of observing it. In other words, observation is a very active process of creation not a passive process of reception and any theory of systems must be prepared to acknowledge - and incorporate - this selfreflexivity into the system.

However, the fact that the observer is epistemologically implicated in any model of self-organizing systems theory is not to say that the model should be theorized with a purpose in mind - such as addressing a social problem (something critical theorists, who following Marx strive to not only describe but change the world might feel inclined to do). 
"A key characteristic of an artificial self-organizing system is that structure and function of the system "emerge" from interactions between the elements. The purpose should not be explicitly designed, programmed, or controlled. The components should interact freely with each other and with the environment, mutually adapting so as to reach an intrinsically "preferable" or "fit" configuration (attractor), thus defining the purpose of the system in an "emergent" way." (Gershenson and Heylighen 2003:610)

I will return to discussing self-organizing system models in the next section. In the remainder of this section I will focus on exploring how ideas that did not originate with systems theory thinking can be incorporated or "translated" into self-organizing systems thinking. 


\subsection{Semiotics and systems theory}

\subsubsection{Peirce's semiotics and systems theory}

According to Peirce (Peirce 1998), the sign arises out of a triadic relationship among an object, its symbolic representation (representamen) and the assigned meaning (interpretant).

"A Sign is a Cognizable that, on the one hand, is so determined ... by something other than itself, called its Object, while, on the other hand, it so determines some actual or potential Mind, the determination whereof I term the Interpretant created by the Sign, that that Interpreting Mind is therein determined mediately by the Object." (Peirce 1998:492)

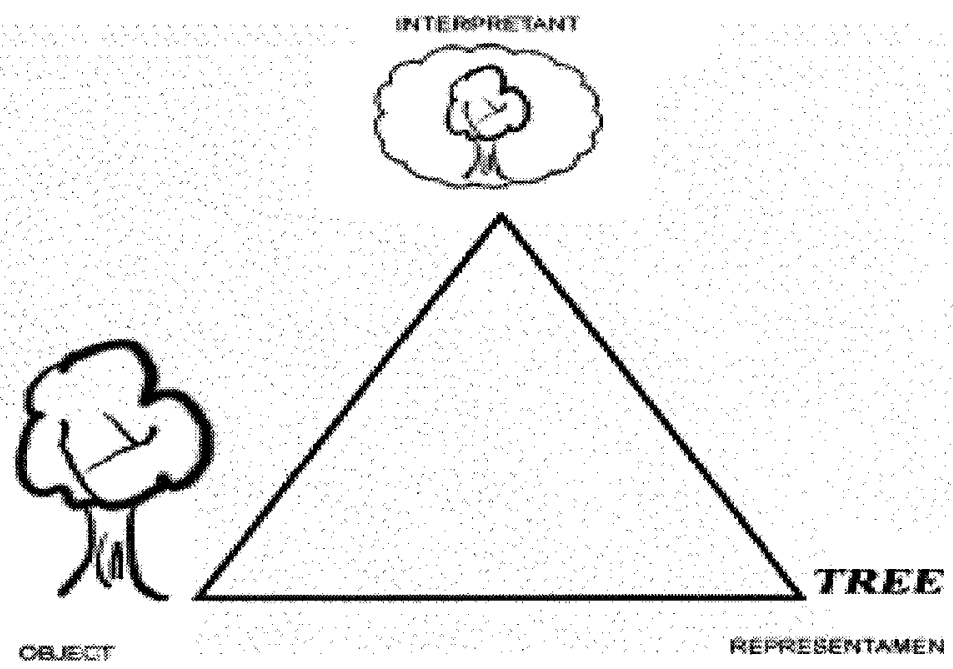

FIGURE 2.6: Peirce's triadic relationship of the sign.

In the process of interpretation, the object becomes a representation (representamen) and, within a particular context of a system of meaning structures, an interpretant with a particular meaning. As the process of signification goes on, representations are worked into the meaning system and themselves become a part of the network of interpretants. And on and on it goes. 
"The meaning of a representation can be nothing but a representation. In fact, it is nothing but the representation itself conceived as stripped of irrelevant clothing. But this clothing can never be stripped off; it is only changed for something more diaphanous. So there is an infinite regression here. Finally, the interpretant is nothing more but another representation to which the torch of truth is handed along; and as representation, it has its interpretant again. Lo, another infinite series." (Peirce 1931:1.339)

In other words, by perpetually becoming interpretants representations come to both constitute and change the structure of the sign. This process of perpetual interpretation and reinterpretation of the sign - termed semiosis by Peirce - is one that is highly compatible with the concepts of emergence and open system. The relation between sign (interpreted) and interpretant, as understood by Peirce, is also a dialogic relation, which is to say a relation characterised by constant dialogue among sign parts a dialogue that never really gets resolved (i.e. a final meaning never emerges) as dialectics would posit (something I look at in detail in the thesis chapter).

Systems theory as it is applied to culture, and as put forward by Luhmann, would follow the semiotics of Peirce who points out that meaning is not defined positively through its content but negatively though its difference from other meanings in a linguistic or in this case cultural system. In this sense, the basic concepts in the theory of self-organizing systems are both identity and difference.

As an example, the story of Oedipus is retold by as many times as the environment in which it is told (audience) changes. Which, without going into philosophical critiques of functionalism - which would resist saying that if something works it is true - is to say the story is different every time it is told by the virtue of the fact that the interpretative framework in which it is received is different. There is a sense, 
however, in which it is the same story that's being retold. It is this tension between identify and difference that dialogic systems theory model will have to grapple with.

Peirce's model of how signs come into being is an improvement on Saussure's signifier/signified binary semiology because by introducing "the object" into the system of signification we can separate meaning from representation, which will enable us to (better) account for shifts in meaning. In other words, Peirce offers us a theory of the sign that rejects the idea of a stable relationship between a signifier and signified, thus allowing us to account for the multivocality inherent in meaning.

\subsubsection{Emergence and open system}

Going back to Goldberg's five common characteristics of emergence (outlined above), it is evident that: (i) new meanings in Peircian semiotics often have features not previously observed in their constitutive meanings, in that meaning arises out of the process of semiosis and as such is a recombination of its constitutive meanings; (ii) the new meanings can maintain themselves over period of time (as evident throught the fact that clearly some sort of communication is possible); (iii) meanings possess the property of "wholeness" by the virtue of the fact that the interpretatnt's meaning is established in relation to other interpretatns as well as to the other two ingredients of the sign, object and representation; (iv) Peirce's conception of meaning is clearly very dynamic, signification constantly moving up and down the signifying chain; and, finally, (v) meaning/sign is "ostensive" in that the change of meaning can be established to have happened (can be observed).

In other words, meaning, as conceived by Peirce, shows all the characteristics of being emergent - a key characteristic of meaning in systems theory. Peirce's triadic sign 
in the manner of its self-reproduction is also an open system for while through its interactions and transformations it continuously regenerates and realizes the network relations that produced them (Maturana and Varela 1973) thus limiting them, it also is subject to continuous input from outside the system (as system "outsiders" come in or the system is forced to react to changes in other systems).

We've now established that Peirce's semiotics is in general compatible with systems theory in that his account of how meaning gets created (as an infinite and unpredictable cycle of code exchange) is very much like the concept of emergence in an autopoietic system.

I would now like to take a look at two kinds of interpretation that take place meaning as an outcome of the interaction of subjective (the individual's relationship to the symbolic) and objective (the symbols relationship to each other) - and show that both of these - both of which are for Kane, who calls them principles of symbolism, a basic premise - are also compatible with systems theory.

\subsubsection{Systems interpretation: Subjective vs. objective}

As Peirce points out, meaning is not a fixed relationship between the symbol and the object it signifies; it is rather a three-way relationship between the object, its representation and the object meaning. But meaning is also unfixed in the sense that it is constantly interpreted by users and thus in the process of interpretation it can and is itself changed.

Interpretation takes place at both the level of the interpreting subject (and in that sense it is subjective) and at the level of the subject interacting with other meaning makers (and in that sense it is objectified or objective). Both of these levels of interaction 
- in essence subjective and objective communicative processes - change as information passes from one system to another.

"If there is a knowledge relationship between two systems, it is determined that there will be causal interactions and structural effects ... but we don't know to which extent this will actually be the case, which new subjective knowledge will emerge, how knowledge structures will be changed, etc." (Fuchs 2004:14)

This understanding of interpretation - as the interaction of subjective and objective systems of knowledge - is exactly what Kane had in mind in what she calls "the second principle of symbolism" which, says Kane, "is that meaning is derived from symbols in relationship to each other." (1997:253) But in systems theory, meaning, in addition to coming from the symbols' relationship to each other, comes from the interaction between systems and the environment (including the interaction between the subjective and the objective).

Furthermore, for Kane, in socio-discursive struggles competing meanings "fuse" to create new meanings (rather than one meaning "winning" over another). Here again, the analogy of a constantly evolving relationship between subjective and objective systems of knowledge, with its emphasis on competition and negotiation (as outlined in more detail in the next section), is quite commensurate with Kane's symbolically "fused" meaning. For Pavlov's dog, for example, the meanings of "bell" and "food" are fused to (in the dog's mind) signify 'I'll get to eat in a minute' and thus making him salivate.

In conclusion, I believe I've shown that Kane's insights into how meaning gets created on the social level, with its emphasis on metaphoric nature of meaning, meaning interpretation as a key process in meaning production and the idea of symbolic fusion of meaning are very compatible with central tenets of the theory of self-organizing complex 
systems, including the concepts of meaning emergence, autopoietic open system and system change.

\subsubsection{Indeterminacy of meaning}

"The struggle of alternative or opposing meanings in the cultural realm of modern society is a double movement, a dialectic of containment and resistance, homogenization and difference." (Fuchs 1995:34)

Indeed, to provide insight into how meaning arises on the social level, the theory of self-organizing systems must conceptualize meaning as negotiable and constantly negotiated. This conceptualization stands in opposition to two other schools of thought, a deterministic and indeterministic.

For cultural determinists (such as Max Horkheimer Theodor Adorno and those close to the Frankfurt School's), meaning is a product of capitalistic mass culture and entirely determined by it. Human agency is thus reduced to peoples' necessarily futile attempts to overcome the system of meanings that shaped and shapes them in the first place (this is analogous to, and would argue originates in, Marx's critique of language (Cook 1982)).

For cultural indeterminists, such as Jean Baudrillard, on the other hand, meaning is so detached from experience that it can be - and often is - simply manufactured. Baudrillard uses the example of the first Gulf War and its coverage by the media to illustrate how the "actual" and the constructed events can have little in common.

\footnotetext{
"[The war was] ... a wargame or simulation, it was then enacted for the viewing public as a simulation: as a news event, with its paraphernalia of embedded journalists and missile's-eye-view video cameras, it was a videogame. The real violence was thoroughly overwritten by electronic narrative: by simulation." (The Guardian, Wednesday March 7, 2007)
} 
The third conceptualization of meaning is meaning as a relationship between the actual (whether the actual is a cultural or a material entity) and the constructed. It allows for - and indeed assumes - that meaning creators (people) can and do interpret the same event/thing in different ways. At the same time, this view posits that the available structures of language and the cultural and material context of its use constrain possible interpretations.

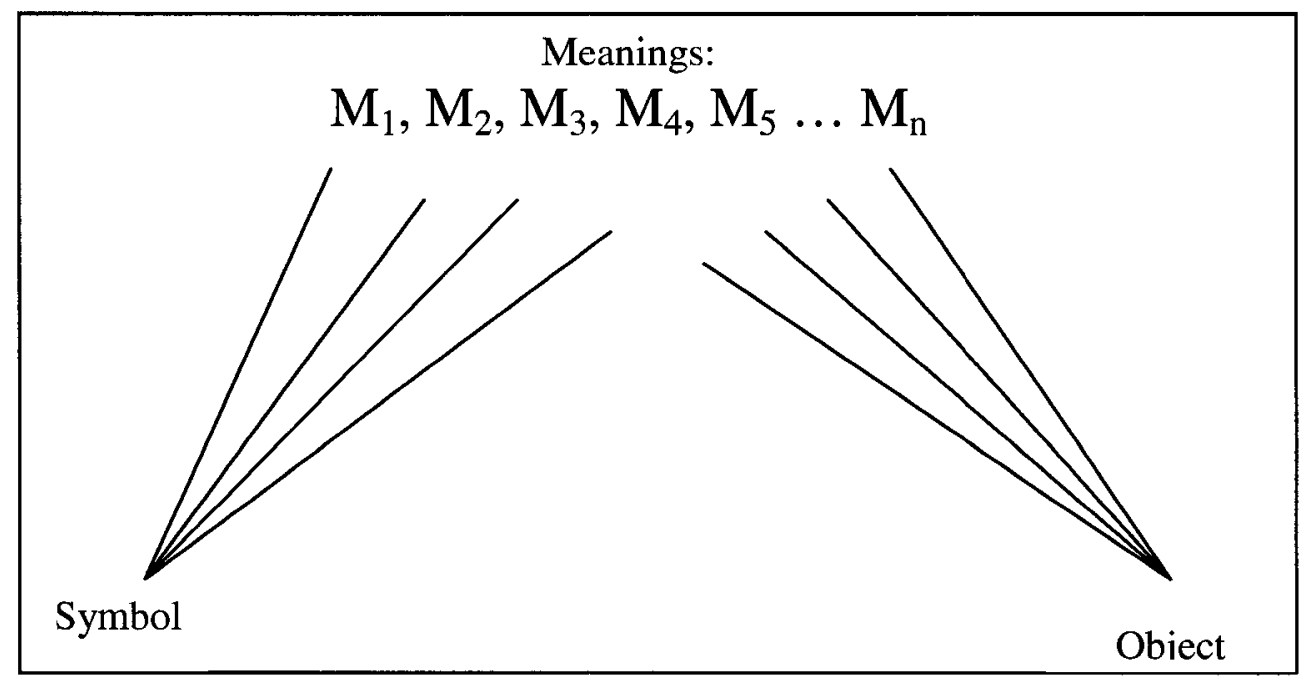

FIGURE 2.7: The above figure shows that an object has "neither one simple meaning nor an unlimited variety, but a conditioned variety of $\mathbf{n}$ meanings that is both multidimensional and limited." (Fuchs 1995:21)

Of course, when one factors in uneven power relations into this view, it will become apparent that not everyone in society has an equal opportunity to determine meanings, and in that sense meaning is an outcome of competitors' struggles to dominate meaning production.

Discourse theorists - frame theorists in particular - pointed out that there exist dominant/hegemonic discourses which attempt to "frame" meanings in such a way so as to "encourage" a certain interpretation. These dominant discourses - which can be seen as systems of meaning interpretation (systems of logics, genres, repertoires, narratives) - 
often have competitors who both attempt to either overthrow the system of meanings all together or, at least, expand its logic to serve the competitors' interests.

This process itself is dialogic in that while "antagonistic social relationships condition a number of possible conflicting meanings of cultural forms" (Fuchs 1995:43), these relationships themselves are conditioned by the outcome of the struggle. This allows for and indeed results in stratifications of power both between dominant and challenging discourses as well as within the systems of meanings (and their users) that constitute them. 


\section{Dialogic-systems theory}

My goal in this section is to integrate what I see as the most insightful aspects of the work of the three theorists discussed in the Literature Review section in a theory that would incorporate the insights of dialogism, as it was put forward by Bakhtin, Peirce's semiotics and with systems theory.

Thus, following Kane's model I focus on the symbolic fusion of meaning; following Steinberg's model, the contested nature of the discursive field; and from Ellingson's model the importance of the event-discourse processes of meaning negotiation and emergence.

I will start out by discussing the (i) difference between dialogic and dialectical processes and move on to outline (ii) the analytical concepts I will use to describe the structure of the discursive field, and (iii) the interaction and eventual change to the field as it interacts with the world through events. I will then propose a model for how meaning changes as a result of a triggering event.

\subsection{Dialogic vs. dialectical}

Both of these concepts are ways of theorizing or conceptualizing change. In a dialectical process, change is a result of a clash between divergent viewpoints, where “one putative solution establishes primacy over others." (Bakhtin 1993:34)Thus, from a disagreement between a thesis and antithesis a synthesis arises, which itself, in time, becomes a thesis.

The antithetical process, as it were, is a dialogic process, where various viewpoints coexist in the same place, interacting with each other and the environment. 
What is different here is that the constitutive parts don't necessarily merge as they interact but rather readjust themselves as a result of this interaction.

Thus, there is no synthesis here, no merging of ideas through conflicts, but on ongoing dialogue between voices - heteroglossia. Clegg, Cunbe and Cunhe (cited in Poonamallee 2006:236) characterise this as a "permanent paradox, while retaining the contradiction and assuming the permanence of paradox." The advantage of adopting the dialogic perspective is that it allows us to acknowledge and benefit from multiple perspectives at once.

The figures below (adapted from Poonamallee 2006:220) represent how the basic logic of change is embodied by both views.

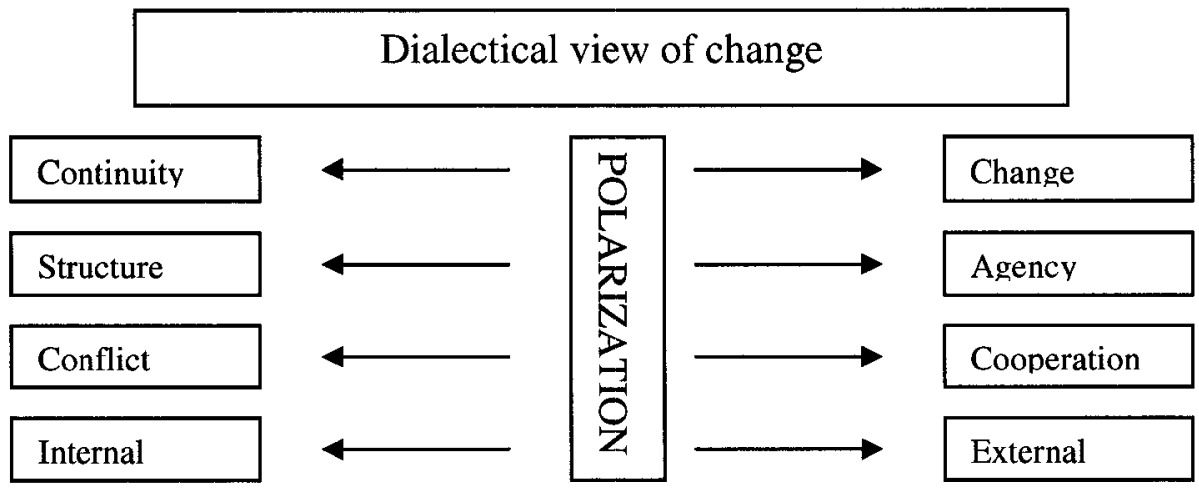

FIGURE 3.1: Dialectical view of change. 


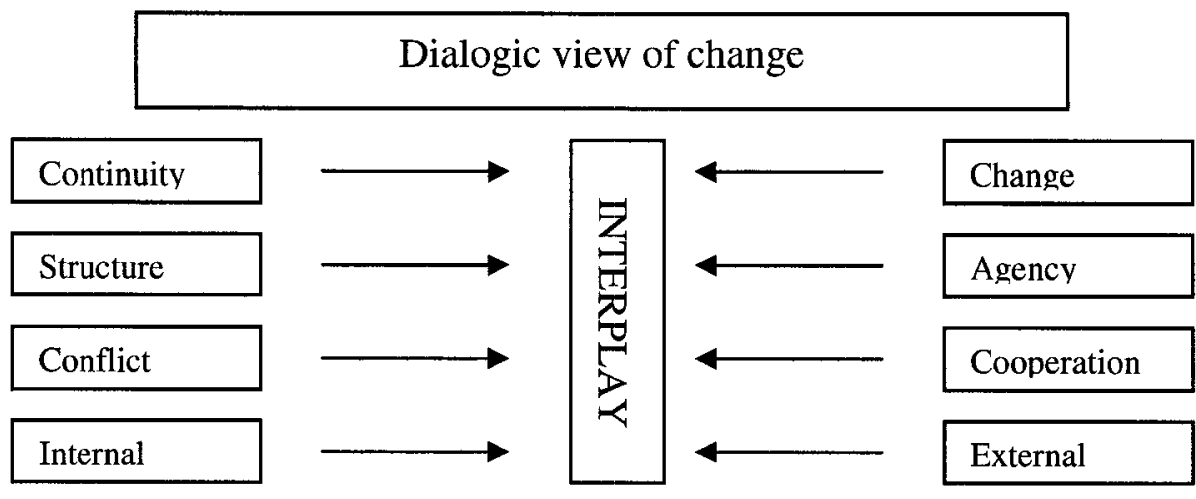

FIGURE 3.2: Dialogic view of change.

Dialogism proposes that an idea or a discourse, "does not merely answer, correct, silence or extend a previous work, but informs and is continually informed by it." (Steinberg 1995). In dialogism constitutive meanings and narratives don't vanish having given shape to other meanings - they are always there constantly informing the emergent meanings.

Dialogism is often opposed to dialectical thinking, which states that out of two competing meanings a third meaning emerges, one which contains elements of the two meanings out of which it has emerged. Once the third meaning emerges, its constitutive meanings are rendered irrelevant, or at best secondary.

As per my discussion of functionalism, traditionally systems theory is seen as a modernist approach that emphasizes how reason structures thought and knowledge, and sees knowledge as linear and progressive. It ignores, the postmodern critics charge, what could be seen as discontinuous and non-rational aspects of meaning emergence.

Dialogism, in terms of epistemological background, is closer to postmodern theory in that it emphasizes that knowledge is relative to the knower, that it depends on the context and that a universalized system in principle cannot do justice to the multivoicedness of reality. In other words, discourse is a (social) dialogue among 
meanings that, in addition to being a part of this interaction, also belong to other interactions - other chapters of reality, as it were - and because of this meanings are in part determined by the context of their system (or use) and in part "somebody else's", which is to say a part of another discursive tradition.

I suggest, however (following Montuori and Purser 1996; Boje and Al Arkoubi 2005), that there is nothing that inherently makes systems theory incompatible with dialogism, and that in fact it would be possible to construct a dialogic-systems theory, whose underlying processes operate in a dialogic fashion. The resulting theory would be considerably epistemologically more humble than original functionalist systems theory and yet it would be more hopeful about the possibility of theorizing about culture than postmodernism posits.

\subsection{What is a dialogic system?}

"A system is a zone of dialogical contact where an organization can be defined as a system of languages that mutually and ideologically interanimated each other ...A dialogic system is an opposition of multiple philosophical views, not a monological synthesis." (Boje and Al Arkoubi 2005:5,9)

In this conception, the aim of constructing a system is not to create a general framework that would "fit" and explain the workings of all knowledge areas - a system of systems (an aspiration of early systems theorists), but rather to construct a model that could describe how a particular system works.

Conceived in this way, a dialogic systems theory approach changes how we understand a system against the background of its environment, emphasizing both "the interconnectedness and mutually constitutive relationship between system and 
environment," (Montuori and Purser 1996:3), which is to say mutually defining relationship of systems.

\begin{abstract}
"After Adam, there are no nameless objects nor any unused words. Intentionally or not, all discourse is in dialogue with prior discourses on the same subject, as well as with discourses yet to come, whose reactions it foresees and anticipates. A single voice can make itself heard only by blending into the complex choir of other voices already in place. This is not only true of literature but of all discourse...." (Bakhtin 1993:x)
\end{abstract}

The dialogic understanding of a system (in that a large part of its systemic identity is derived from its embeddedness in a particular environment) allows us to replace the traditional monologic, rational and univocal systems with polylogical and unfinished ones; more than that, however, it allows us to see system dynamics (dialogue) "not a simple exchange of voices, but rather an exchange of perspectives" (Boje and Al Arkoubi 2005: 9).

Finally, as Yazdanpour (1998) points out, "Bakhtin's concept of dialogic can be read the same as dialectic without synthesis. There is no end to the tension between the opposed forces. In the first place it is, for Bakhtin, naive to see the forces as only two; rather, there is a plurality of forces." 


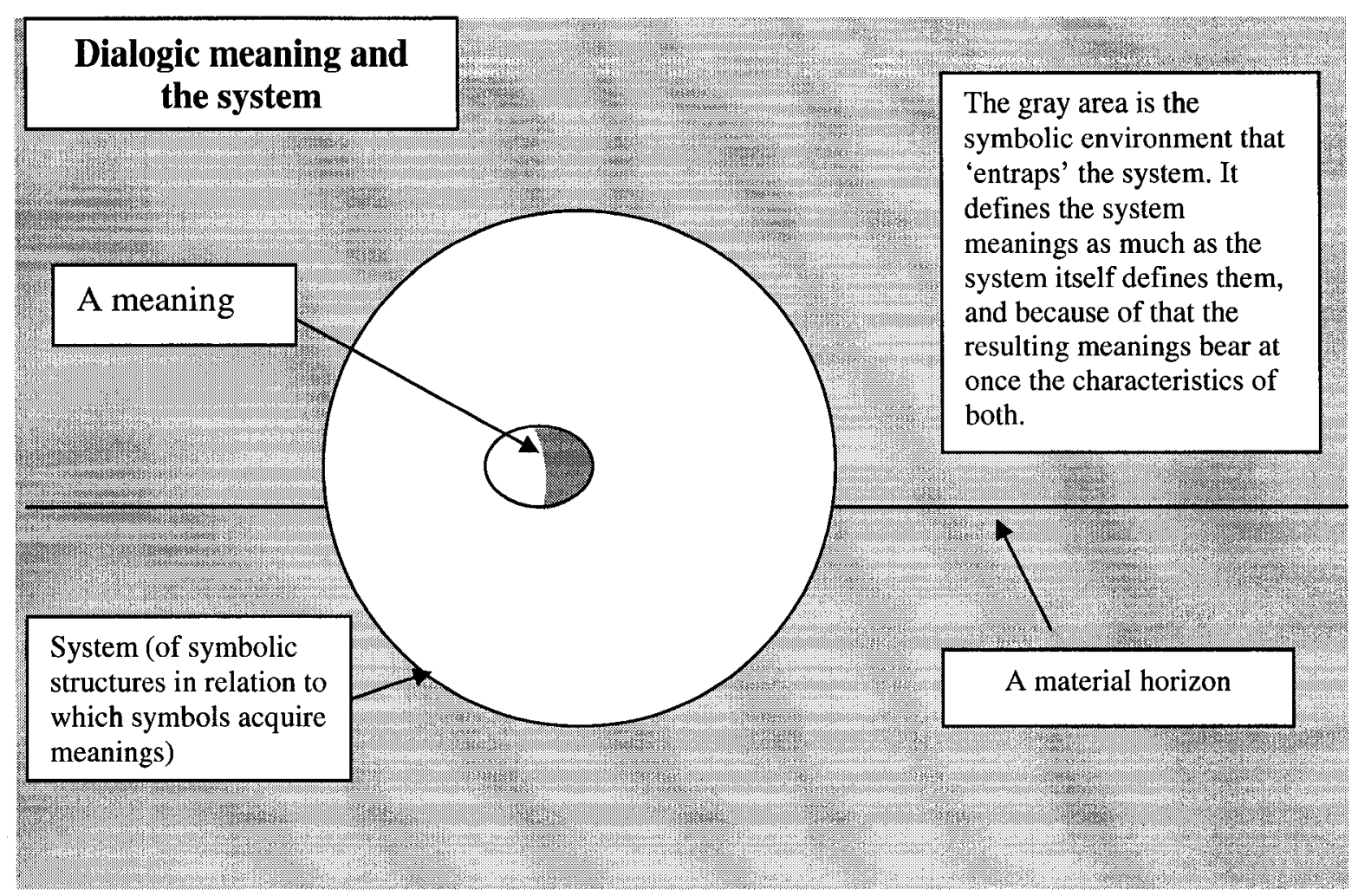

FIGURE 3.3: Meaning in systems theory is dialogic in that it arises out of the interaction between the system and the environment, retaining the characteristics of both.

\section{The material horizon}

To do justice to this interconnectedness of system and the environment, a systems theory of how meaning arises on the level of society must acknowledge, in addition to the semiotic environment (that accounts for how symbolic systems are put together and change), the existence of the material environment (something postmodern theorists would presumably be disinclined to do). This is necessary because culture is a relationship between the real and the symbolic, as much as it is a relationship among symbolic systems.

Indeed, if we don't posit a materialist component (the horizon) in meaning formation, we would introduce a basic disconnect between the mind and matter (something Marx, for one, would take offence to), and allow discourse to be responsible 
only to itself (its own logic and memory) without regard for the material aspects that limit it.

More can be said about the materialist-idealist debate, but the key question here is not whether either worldview is right, but whether the materialist view can accommodate the theory of systems. Like many others (Luchmann, Fuchs, Lemke, Gershenson and Heylighen) I believe, as I have shown it can in my discussion of Peirce's semiotics and dialectic, that it can.

\subsection{Dialogic-systems theory and power}

As mentioned earlier, and despite charges to the contrary by opponents, dialogic systems theory is "aware" of power relations within a system to the extent that the system conceived as dialogue among participants is able to recognize that as systems of meaning reconstruct realities the reconstruction empowers certain individuals while sidelining others.

In other words, while theoretically any discursive system can reconstruct any other system in terms of its own logic, in society some systems are more powerful (by whatever virtue) than others and are thus in a better position to put forward their meanings as legitimate (and not vulnerable to others' reconstructions). In this way dominant systems get to determine what constitutes legitimate knowledge as it pertains to culture, politics, the environment - and what does not. Challenging discourses, of course, are trying to undermine this interpretation of reality by proposing their own interpretation, by trying to "sell" their version of reality to gain social power, but need to resort to alliances, trying to "create" facts or attempting to otherwise undermine the dominant speakers to become relevant. 
Another aspect of power to which dialogic systems theory is well attuned - as mentioned before - is that of self-reproduction of power. This is to say that all systems of meaning (i.e. dominant or otherwise) produce meaning so as to not only dominate the competitors (and the public sphere), but also to remain in power. This is evidenced by the fact, pointed out by many a feminist, that institutional language tends to reflect social power relationships, but also reproduce them. In other words, dominant discourse would perhaps sooner change its ideology than propose a discourse that would in effect undermine its power hold on social meaning making.

Lastly, and also contrary to charges by critical theorists, dialogic-systems theory has the capacity to recognize that contradictory discourses, narrative discontinuities and pauses are as much a part of the logic of the system as continuities and rational discourse. This is because unlike dialectic which demands that one meaning become dominant, dialogism allows for - and indeed posits - multiplicity, variety and recombination in discourse.

\section{Centrifugal and centripetal forces}

In Bakhtin's conception of dialogism, the dynamism of dialogic change - the interplay between change and continuity, agency and structure, etc. - is propelled by the existence of centrifugal and centripetal forces in discourse. While the centripetal force unifies and ideologically common-denominates and centralizes language (trying to make it homogenous), the opposing centrifugal force establishes the discursive systems presence in heterogenous environment. The figure illustrates the operation of the centrifugal and centripetal forces on the discourse (Figure 4.4). 


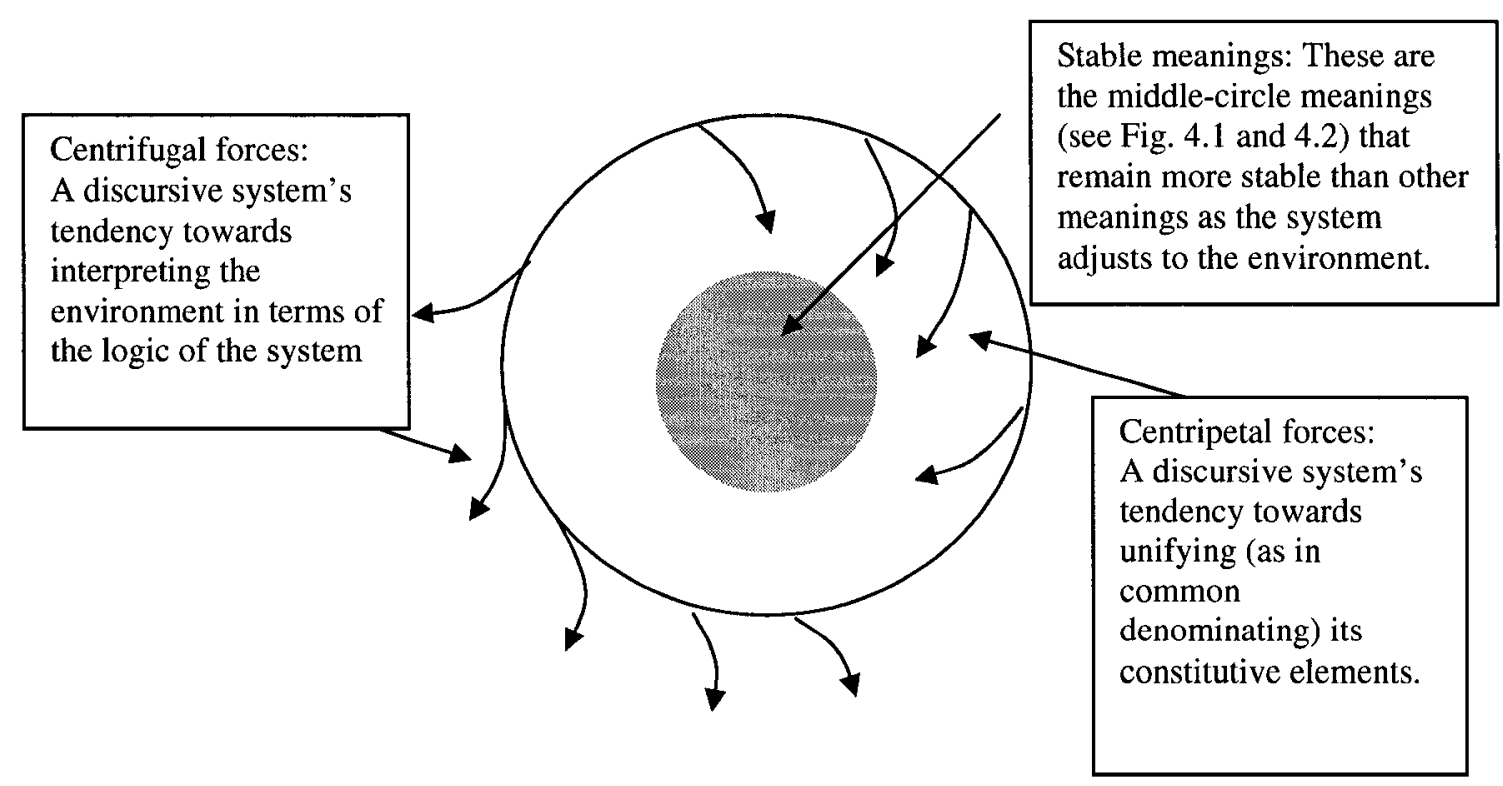

FIGURE 3.4: The operation of centrifugal and centripetal forces on discursive system.

The forces in FIGURE 4.6, provide a forum on which change as seen from a dialogic perspective can take place (FIGURE 4.5), which is to say it allows for the interplay of continuity and change, structure and agency, cooperation and conflict, the internal and external aspects of communication. Discourse here is not based on polarization of narratives (as in dialectic), but rather an outcome of a "collapse" and structuring of the different narratives. According to Bakhtin (1981:272):

"Every utterance participates in the "unitary language (in its centripetal forces and tendencies) and at the same time partakes of social and historical heteroglossia (the centrifugal, stratifying forces). Such is the fleeting language of a day, of an epoch, a school and so forth. It is possible to give a concrete and detailed analysis of any utterance, once having exposed it as a tension-filled unity of two embattled tendencies in language."

\subsection{Discursive system structure}

Discursive system (or field) delimits the boundaries of possible cultural action and understanding, and presupposes a shared reality among those who partake in it. 
Discursive field consists of categories that impose structure on meanings, not of the meanings themselves; it is negotiable and indeed negotiated with opponents, and is evident in continuity and discontinuity of history and institutional structures (as per Foucault's analysis of prisons in Madness and Civilization, for example). Discursive system is a system in the sense that it's a collection of genres, logics and narratives available for addressing a particular issue. In this way it is similar to the concept of master frame in framing theory.

Genres and narratives are "the stuff" that makes up the discursive field: the logics, systems of vocabularies and grammars, types of arguments, discursive rules, systems of knowledge from which any group can choose to form its own systems/structures of meanings. They can be political, economic, social, historical, religious or any combination of these.

Repertoires are the particular combinations and patterns of meaning that a group creates from genres and narratives. Repertoires are not so much chosen as strategically (and dialectically) negotiated between the group's speakers and audiences at the level of ACTUAL DISCOURSE. Repertoires of challengers are often, to some extent, appropriations of the dominant repertoires as the challengers don't have the institutional, cultural and social standing to legitimize their own meanings.

Actual discourses can be said to be actual forms of argument picked by groups or leaders from repertoires. In other words, these are the actually used forms of argument picked from repertoires. I will show later (and in the attached diagram) how this addition to the theoretical framework can help us conceptualize the negotiation of meaning as a dialogic process which, through negotiation and contestation, can change meanings. 
Levels of organization are different levels on which discourses can self-organize. In linguistics, for example, a sentence can be said to be organized on the lexical level (how words interact), the morphological level (how internal word structures interact) and the semantic level (how meanings interact). Similarly, discourses can be said to be organized on many levels depending on the basic units we're interested in.

Agency is the actor's capacity to transcend the constraints of habitus, the capacity to transpose and extend rules/schemas to new contexts, the capacity to reinterpret and mobilize an array of resources in terms of cultural schemas other than the those that initially constituted the array.

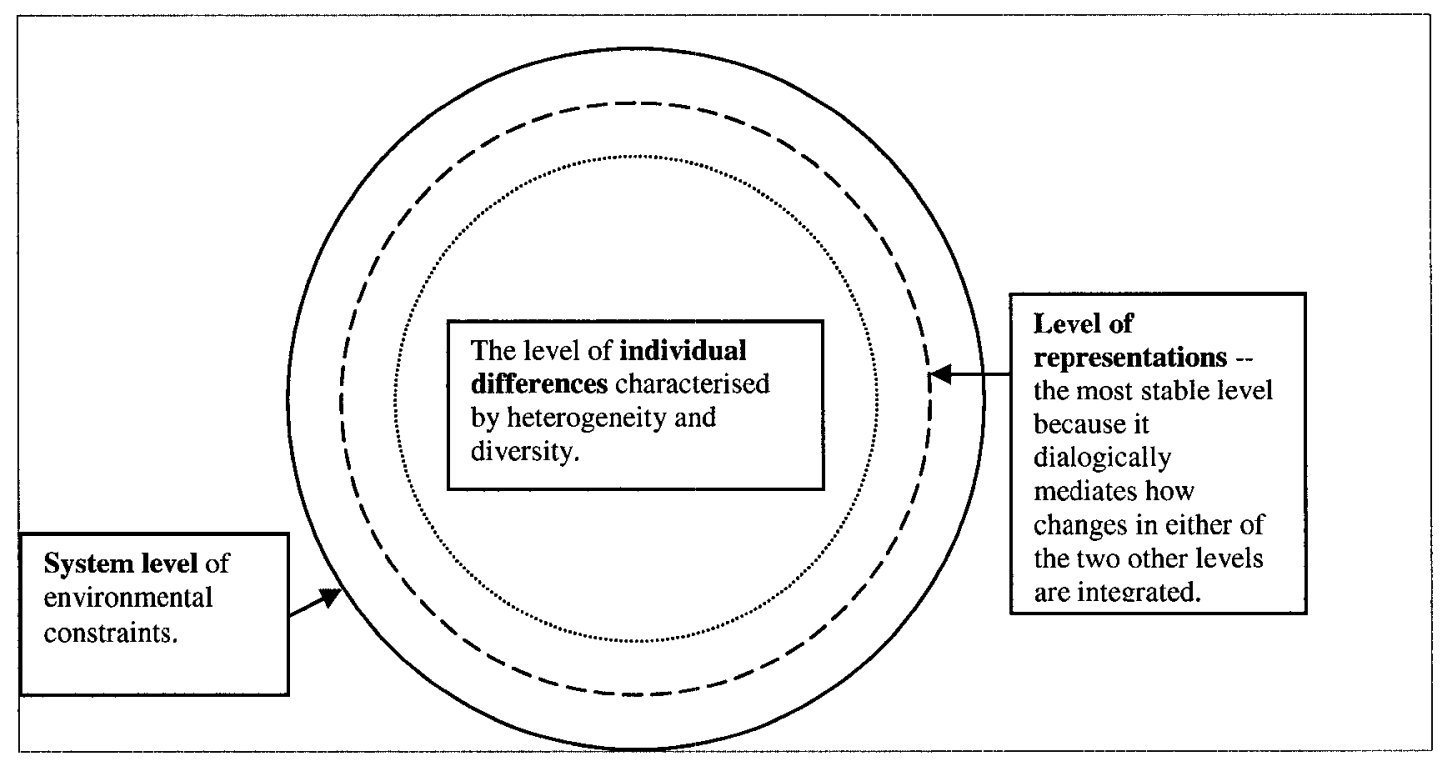

FIGURE 3.5: Discursive system levels and hierarchy 


\section{System dynamics and semiosis}

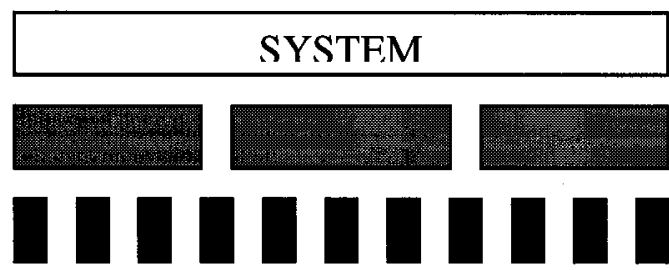

Interpretant level: constraints, environment

Representations level: objects from level below are filtered/buffered for interpretation above

Object level: constitutive elements

FIGURE 3.6: Hierarchies of discursive field scale in complex systems (adapted from Jay L. Lemke 1993).

The logic of this interaction shows how all levels of interactions in the system depend on each other. So the smallest circle (the object level), which represents particular discourses or genres that constitute the system, constitutes the phenomena in the middle level. On the other hand, the phenomena on the interpretant level (large circle), constrain the middle level and are themselves constrained by the environment.

As an example, particular environmental discourses - the militant discourse of Greenpeace and the more mainstream discourse of the David Suzuki Foundation - both belong to a broader system of environmental discourse. This environmental discourse, however, is itself constrained by its broader socio-cultural environment, where a number of other stakeholders fight for public attention when it comes to environmental issues (oil companies, car manufacturers, grassroots stakeholders).

The above is a frozen in time view of the process. In reality, new levels of organization emerge between the largest and the smallest circle all the time, as the middle circle constantly reorganizes the relationships between them. In other words, the real process is very dynamic and characterized by constant interaction between speech acts and language (and discourse) structures. Below is an illustration of how more abstract 
levels of organization, genres and narratives, produce more concrete templates for language use (repertoires) and how those in turn interact with the environment (via actual discourse) to produce feedback fed back into the system (which allows it to adapt to changes in the discursive environment).

\section{Discursive system feedback structure}

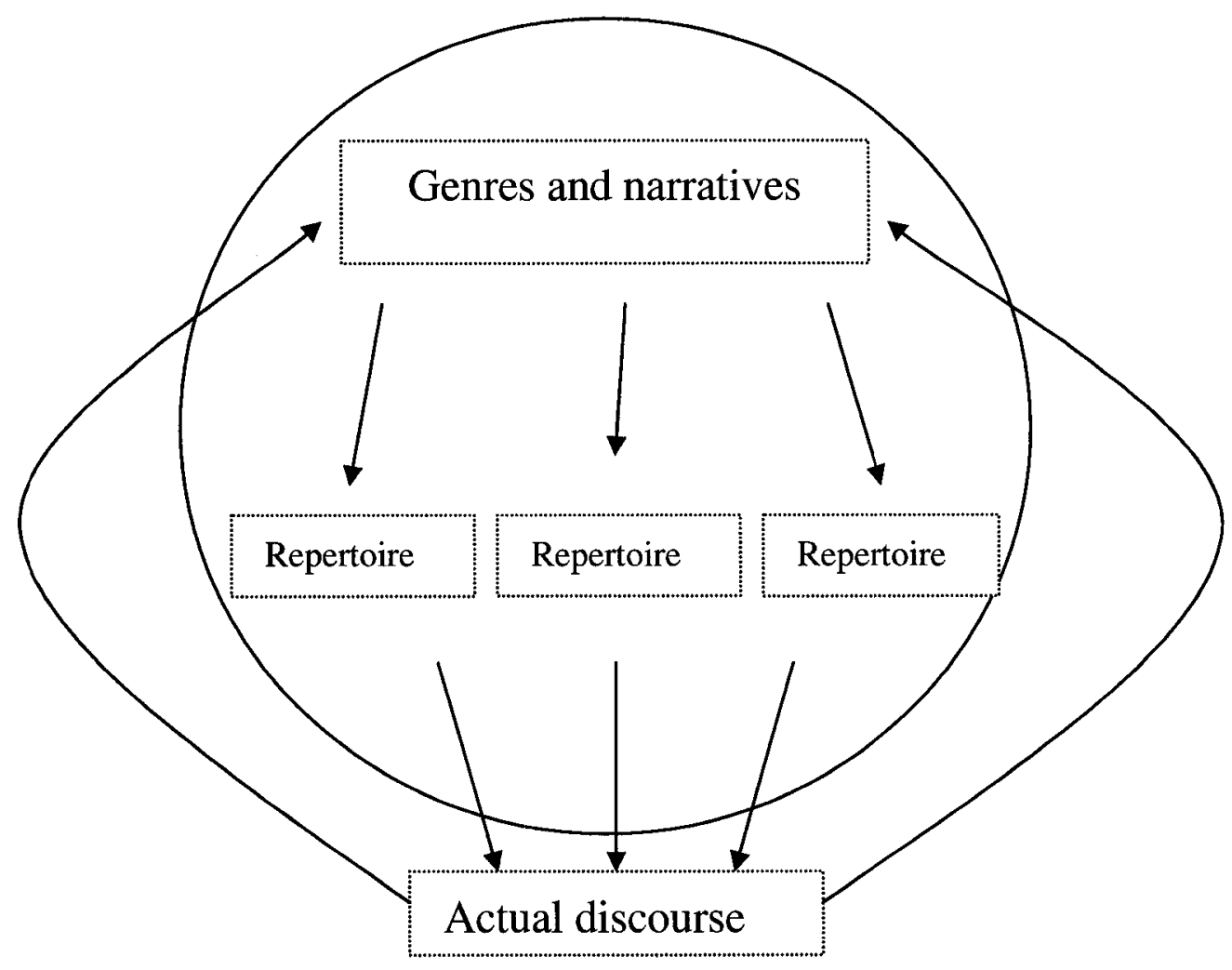

FIGURE 3.7: The feedback structure of the discursive system.

\subsection{Discursive system dynamics}

Before proceeding with a description of the nature of the change to the discursive system, I will first outline a few more key concepts, including event, change, imperative of differentiation, heteroglossia and process. 
Other key concepts

Event is an occurrence or a critical weight of a set of conditions/occurrences that necessitates a reorganization of a discursive system - by both the dominant and challenger discourses. It is a phenomenon that both cannot be incorporated into the old discourse/system (in that it somehow contradicts its logic) and can't be ignored (in that it is self-evident, like climate change or poverty). The concept of event plays a critical role here in that an event is a necessary and sufficient catalyst for change in the system of meanings.

Change is an adaptive system response to change in external environment to preserve its basic system structures (here symbolic meaning structures). Change triggers actions both inside a discursive system (such as power struggles among leaders) and between discursive systems (trying to win wider public support for system meanings).

Imperative of differentiation is the principle for new discourse formation and negotiation. It stipulated that because new discourse is formed in a preexisting discursive context (rather than in a vacuum), when two distinct discourses are re-forming after an event they must be sufficiently different to justify their raison d'être.

Heteroglossia or multilanguagedness describes the coexistence of distinct varieties within a single linguistic code; multiple "languages" within a language. Tension and conflict characterise their co-existence. It results in dialogism - a dialogue among forms of language (not people) or between languages.

Centrifugal and centripetal forces in discourse are the forces by the virtue of which the system can identify against the background while at the same time acquire new information and share its information with the environment. Thus the centripetal force 
tends to push things toward a central point (thus creating stable meanings), while the centrifugal force tends to push things away from a central point.

Process is the way in which meanings and boundaries of the discursive field get established, negotiated and renegotiated. I divided process into four parts:

1. Pre-event equilibrium: this is the approximate balance of power (and meanings) before the event (the dominant discourse may dominate the system, but it is kept in check by the fact that the contenders are constantly trying to challenge it - which is to say by its environment);

2. Event: a critical weight of a set of conditions/occurrences that necessitates redefinition of discourse;

3. Renegotiation of meaning: happens when there is an attempt to accommodate the EVENT within discursive fields;

4. Reconstituted equilibrium: the post-negotiation equilibrium, in which, for example, a challenger can become dominant or, more likely, acquire power to more substantially influence the discursive system.

\subsection{Multiple discourse dynamics}

In his model, Ellingson offers a dialectical model for how meaning systems (discourses) interact and shape events, which in turn changes the meaning systems themselves. The shortcoming of his model - which in so far as it deals with the problematic of discourse vs. action is an improvement on both Kane and Steinberg - is the fact that dialectic by its very nature sees the meaning-making process as linear. Here, out of the tension between discourse and action arises a new discourse whose structures are an improvement (in an adaptive sense) on the old structures. 
In this section, I want to sketch out a model that could be based on dialogism as opposed to dialectic. As opposed to dialectic, dialogism, as I explained in the previous sections, insists that meanings in a meaning system are in a force-field of sorts rather than in a hierarchy. This isn't to say that there is no hierarchy in a discursive system, but that the hierarchy that exists is a highly unstable and contested process, and has a potential of significantly and unpredictably changing in a short time (which isn't to suggest that it often does).

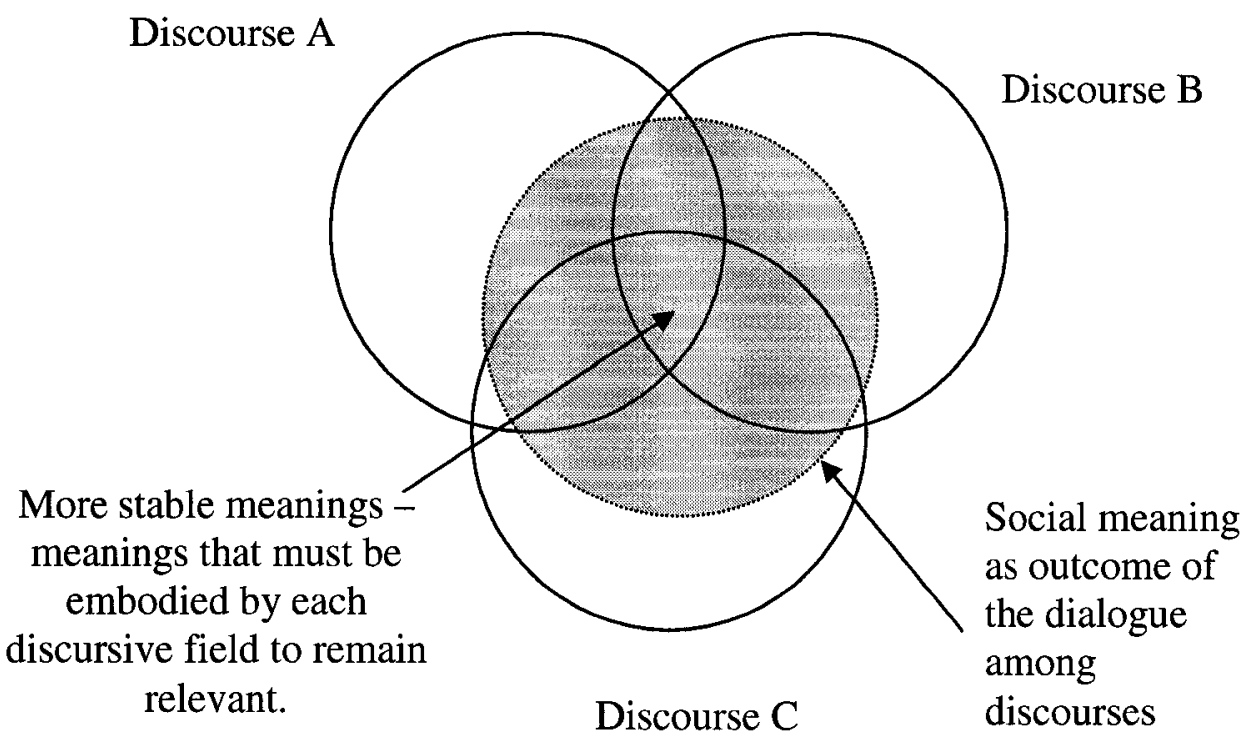

FIGURE 3.8: The process of distinct discursive systems coalescing into a discursive field.

The above is a coalescence of discursive systems around a particular issue. So, for example, the environmental movement, the government of Alberta, the native communities and the industry are all attempting to "hijack" the discourse-making as it pertains to the exploitation of the oilsands in northern Alberta. As a result of the clash between all these systems of meaning, all of these meaning-makers are contributing to 
actual public sphere meanings, but - and perhaps more importantly - to changing the rules (i.e. both practices and structures) that govern the creation of that meaning. In consequence, the public sphere meanings surrounding the exploitation of oilsands will tend to have elements of each of those discourses and often operate according to contradictory logics. For example, people may tend to think that it is wrong to disenfranchise the Aboriginal community and pollute the environment in the process of mining the oilsands, and at the same time hold that it would be wrong not to develop the oilsands resources or charge the industry "socialist" taxes. It is in this way that dialogism allows us to see discourse as discontinuous and contradictory while at the same time ordered in accordance with the principles of dialogism. 
Multiple discourse dynamics: The process

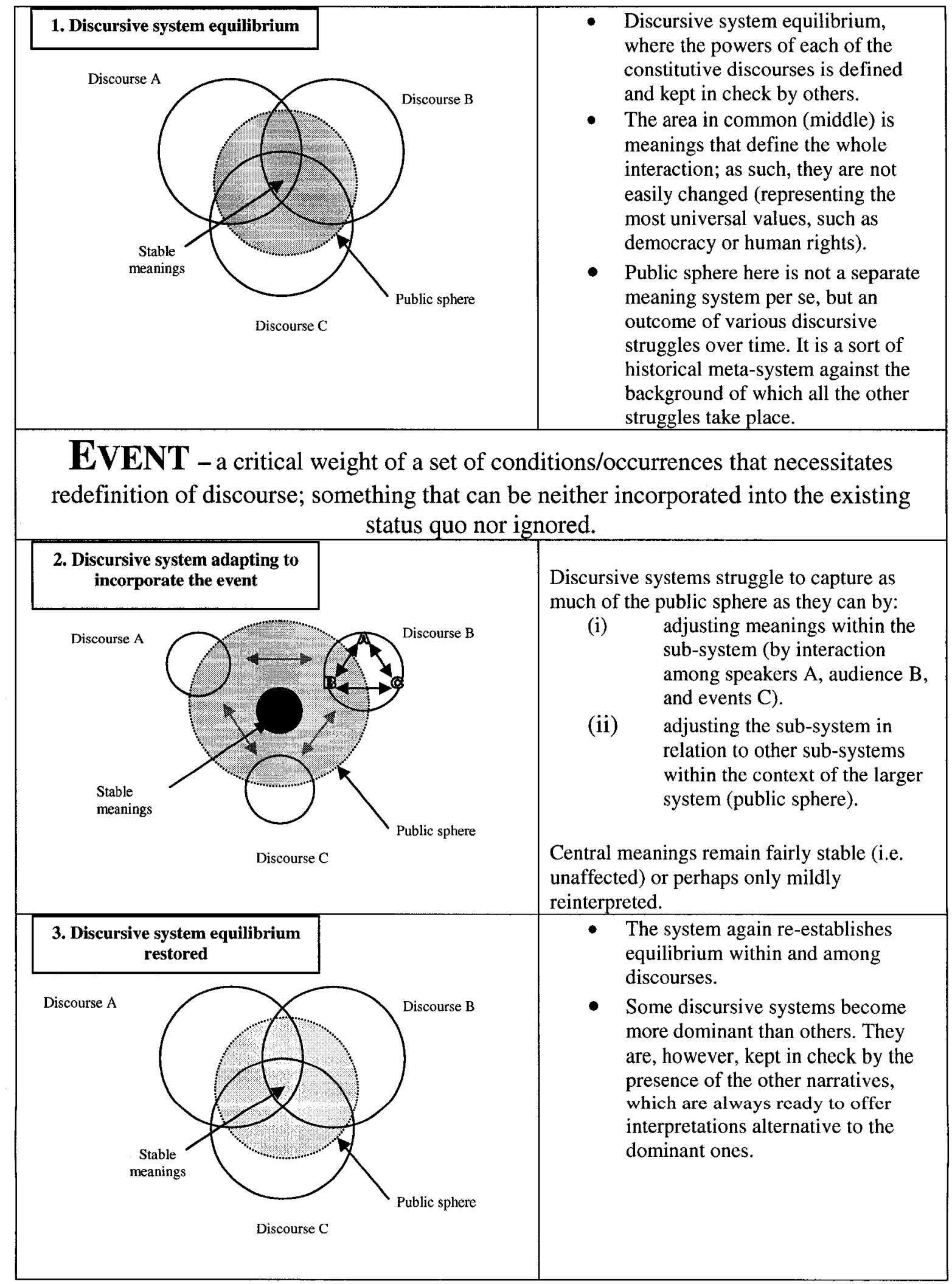

FIGURE 3.9: Discursive system equilibrium 
The first move in the diagram describes the nature of a discursive struggle before the event takes place. Because the challengers don't have the institutional and social standing to legitimize their oppositional meanings, the negotiation of meaning in this first phase is a slow process (theoretically non-existent). However, when an event takes place, it is an opportunity for challengers to offer their own meanings more forcefully (as there is an unresolved tension between the dominant discourse and "the facts"), sometimes allowing the challengers to take over as the dominant meaning makers as was the case during the Irish Land Wars (or the French Revolution).

The sponsorship scandal in Canada could perhaps provide a useful example here. The scandal - an event - allowed the challengers to point out contradictory meanings in the dominant meanings, creating (obvious to the public) dissonance between the Liberal party's rhetoric and their actions. The challenging interpretations were not immediately accepted by the audiences. But over time, through the constant process of negotiation and renegotiation of the meaning of the event - and because the discourse attempts of the Liberal Party couldn't convincingly accommodate the event - the challengers' interpretations started sounding more reasonable and, eventually, became dominant (in so far as the interpretation of the event was concerned).

What's important to point out is that the winning discourse (winning discourse, of course, doesn't mean Conservative; it was shared by the NDP and the Bloc Québécois) the discourse that took over the discursive field with its own repertoire - managed to get ahead by re-appropriating the meanings, which is to say by fusing existing and new symbolic narratives rather than simply proposing new ones. In fact, it has been argued that it is only after the challengers started listening and dealing with the dominant 
discourse (which isn't to say the actual arguments put forward by the Liberals, but rather working inside the realities allowed for by their discursive system) that they became successful at dethroning it.

The second move in the diagram illustrates that for competing discursive systems to remain relevant to the audience, they need to account for the event in their discourses, but also provide different event interpretations if they want to survive as separate. This is to say these systems need to establish rules of discourse that both serve their interests (by, for example, expanding the debate to include their genres of interest) and are different from the opposition. This is in accordance with Ellingson, who says: "Because discourses are created in reference and opposition to one another, an imperative of differentiation characterizes the process of creation and contestation." (Ellingson 1995:132)

The new post-event discursive systems, however, will need to resonate with their audiences. That's why both dominant and challenging speakers will negotiate the new discourses with their audiences at the level of argument (argument being at once the building block of discourse and an act that diagnoses the problem and offers a solution (Steinberg 1995:121)).

In this way speakers collaborate with audiences to interpret and assign meanings to the event, and the speakers will modify their positions depending on the arguments of the public and the opposition, keeping in mind the imperative of differentiation. As a result, the finalized post-event meanings are in fact combinations of pre-equilibrium meanings, which is in essence very much like Kane's idea of fusion of meaning, except that in dialogic-systems theory the new meanings are also a diffusion of the old ones (not just fusion). 
Thus, new post-event discourses and discursive fields end up as combinations of those that previously existed (but now have been negotiated through a dialectical process and have thus changed), and perhaps include some new narratives and genres that the event interpretation has forced the dominant meaning makers to bring in. 


\section{Empirical example: Irish Land War}

The Irish Land War was a prolonged period of civil unrest in Ireland in the 1870s, 1880s, and 1890s. It was led by the Irish Land League - an Irish political organization which sought to help poor tenant farmers by abolishing the English-supported "landlordism" and enable farmers to own land on which they worked.

The Irish Land War begun as a farmer protest movement against high rents, evictions and landlord refusal to decrease rents in the face of a Europe-wide economic depression of the late 1870s. However, the Irish nationalists quickly realized and seized the opportunity to fuse - on the ideological level - the farmers' general disillusionment with landlordism as agrarian and, by extension, social policy with nationalist ideals.

The effect was a mass mobilization of many Irish stakeholders - the farmers, the clergy, the political leaders - essentially forcing the British to, as a way of reform, enact the Land Act of 1881. (Whereas before the Act the landlord had absolute rights to the land, the Act established commissions to determine fair rents and allowed tenants the right to sell their interest in a holding, creating in essence a form of land co-ownership.)

But perhaps more important than the Act itself was the movement's eventual outcome - the fact that old-style landlordism in Ireland was effectively terminated and the independence movement was deeply rooted in the Irish consciousness.

The Land War, Kane suggests, is an excellent example of how the cultural events (that is to say changes in the ways people see their world - and in how they define their problems) can lead to social action. Indeed, the success of the land movement is an illustration of how culture (and thus meaning) is not necessarily an outcome of social and 
economic structures, but an analytically independent force that deserves to be studied alongside the aforementioned structures.

\subsection{Key participants (meaning-makers)}

The British rule was never particularly popular among the Irish, but the divergent interests and perhaps more importantly divergent worldviews among the key cultural/political stakeholders of the time - the Irish nationalists, tenant farmers and the Church - (which were a result of their different experience of the British rule and the interest of short-sighted self-preservation) made a unified movement unlikely.

The divergent interests characterised not only between these groups, but, as Kane points out, were apparent inside the groups as well. "These groups [were] fragmented internally along "class" - small, middle and large farmers; political - constitutional federalists and radical separatists; and doctrinal - ultramontane and Irish patriotic (within the Galican tradition) - lines." (Kane 1997:259)

According to Kane (1997), the idea for recruiting the farmers who were hardest hit by the depression (i.e. the poorest farmers in the western province of Connaught) into a movement came from the Irish nationalists who "understood the urgency of the land question and it could be used to mobilize the majority of the Irish against British." (Kane 259:1997). They were the ones to organize the first public meetings and bring the issues to the attention of the elected Irish politicians.

The resistance the land movement initially encountered from the more better-off and politically moderate farmers was eventually overcome by the confluence of three events: The deepening of the economic crisis (and, more particularly, the government's effort to provide relief for the poorest farmers angered the larger farmers); the 
government's arrest and charging with sedition of the land movement's leaders; and the fact that Archbishop Croke of Cashel, "an ardent nationalist and defender of tenant rights," publicly endorsed the movement.

It can be said (Kane 1997) that with this confluence of events, what began as the small farmers' general disillusionment with the agrarian policy status-quo, coalesced into a full-fledged movement that found sympathizers in the majority of all farmers, and was supported - and lead - by both the Irish nationalists and the Catholic church.

Some of the activities that indicate the coalescence of the movement include demonstrations against evictions; legal actions in courts; opening up of local Land League branches, parliamentary actions, which included reform proposals and intimidation tactics. According to Kane, the most symbolic of these activities were the huge mass meetings (rallies in essence) that brought together between 2,000 to 20,000 people from variety of professions - farmers, labourers, merchants, professionals - and were led by farmers' and nationalist leaders, the clergy and Irish MPs.

It is these meetings - highlighted by speeches infused with Irish myths of conquest, confiscation, repression and famine - that were, according to Kane, the principal venue for the symbolic struggle and meaning appropriation and reconstruction.

\subsection{Symbolic struggle of the Land Movement}

At this point in the land movement's life, while there was a general consensus among the stakeholders that land reform and independence from the British were its principal aim, few leaders and interest groups agreed on just how to go about accomplishing it. Some of the contentions included: "Should the movement follow a strategy of moderate agitation and parliamentary pressure, or should radical methods, 
including violence, be followed?" and "Should land reform follow a program of copossession with landlords ... or should the landlords be dispossessed of their land immediately?" (Kane 1997:16)

These differences were a result of the fact that while the movement participants agreed that the Irish had the right to their land and independence, their symbolic understanding of just what that meant were different. And so, "To the smallest Irish farmers, land provided and represented stasis of tradition and a communally based form of agrarian organization ... [whereas] to the commercialized middle-size and larger tenant farmers, security through the land meant economic opportunity and social and political mobility."

The symbolic divisions were also apparent among the nationalists for the more radical of whom land represented independence and freedom from the British rule whereas for the more moderate it meant "democracy and self-determination in Irish affairs" (Kane 1997:163). The Catholic Church, too, was divided. While the senior clergy was anxious about violence and loss of political control, the majority of priests were sons of the farmers and sided with their parishioners.

Through many of the mass meetings - "sometimes up to ten meetings on any given weekend" (Moody 1981; Townsend 1983 in Kane 1997:17) - these internal tensions inside the movement eventually polarized into two opposing discourses, or what Kane terms "the discourse of retribution versus the discourse of conciliation".

These two discourses, one radical the other moderate, would now set the tone for the discussions within the movement, and operate as symbolic templates around which new understandings for action were developed. Thus the discourse of retribution, which 
dominated the participants' sentiments, came to symbolize "compensation, redress and justice" and would present the discourse of conciliation as "inability to take a determined stand against the injustice." The discourse of conciliation, on the other hand, "patience leading to gradual and steady change," emphasized that the existing legal framework were more than capable of addressing these issues to the satisfaction of most parties involved.

The clash of the two discourses during the mass meetings - or as Kane terms it "symbolic collision" - was how "meaning transformation, convergence and ideological consensus" was achieved. In other words, through the emergence of this symbolic dichotomy, the stakeholders' symbolic worlds were given both the forum for expression and a chance to accommodate and be accommodated within the movement's developing discourse and identity. 


\subsection{Dialogic-systems theory model for Irish Land War}

What follows is a figure (Figure 4.3) that illustrates a systems theory interpretation of the Irish Land War. It includes four steps:

1. pre-war system equilibrium

2. discursive systems' adaptation to the event - the creation of the movement

3. the new challenger (land war movement) starts making meanings in the public sphere

4. equilibrium is re-established 


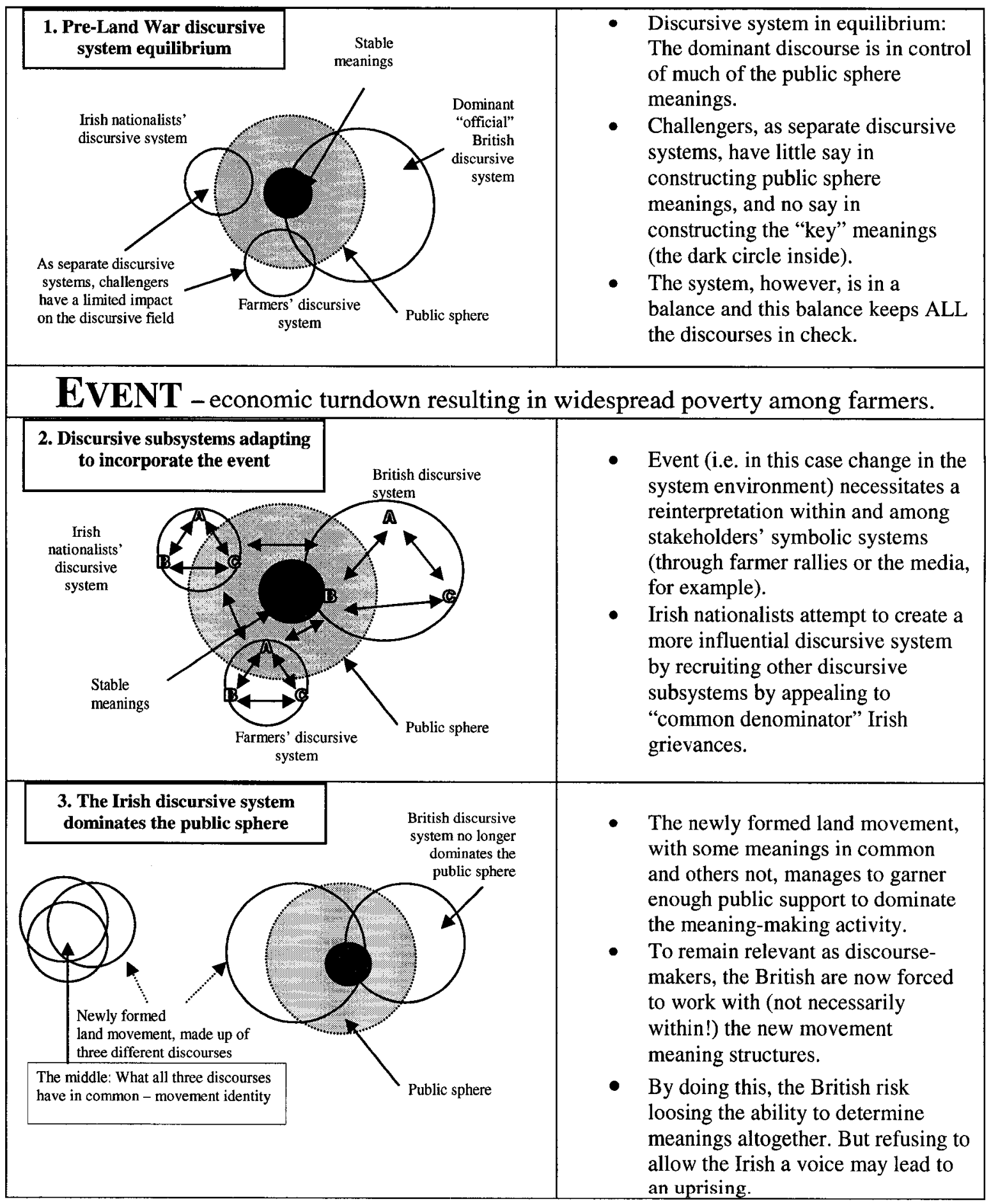




\begin{tabular}{|c|c|c|}
\hline $\begin{array}{c}\begin{array}{c}\text { 4. Re-established discursive } \\
\text { equilibrium }\end{array} \\
\end{array}$ & $\begin{array}{l}\text { British discursive } \\
\text { system no longer } \\
\text { dominates the } \\
\text { public sphere }\end{array}$ & $\begin{array}{l}\text { The system again re-establishes } \\
\text { equilibrium within and among } \\
\text { discourses. } \\
\text { After the equilibrium is re- } \\
\text { established, the common meanings } \\
\text { that were kept out of the public } \\
\text { sphere in the past are worked into } \\
\text { the public sphere symbolic } \\
\text { structures, and so the differences } \\
\text { among movement stakeholders } \\
\text { become more apparent. }\end{array}$ \\
\hline
\end{tabular}

FIGURE 4.1: Dialogic-systems theory interpretation of the Irish Land War. 
Strategies for changing the equilibrium

As I mentioned in the previous section, because the large chunks of the discursive system are often controlled by the dominant discourse, the challengers' views often can only become relevant in so far as they indulge it. If they do decide to indulge it, however, they allow themselves a few strategic moves that could challenge the dominant meanings.

Strategic moves can include coming up with knowledge that's relatively selfevident and not included (or rather not accounted for) in the dominant discourse (global warming) or somehow undermining the speakers' credibility as legitimate meaningmakers (as per the sponsorship example). These strategic moves could open up the discursive field (perhaps even trigger an EVENT) to enable the challengers to include rules for meaning formation that represent their interests and undermine the interests of dominant discourse, thus furthering their interests both in terms of a particular issue and an increased stake in the public sphere.

System speakers can also play an important - if often unpredictable - role here. According to Ellingson, some of the strategies used by speakers can include: shifting the definition of the situation from a specific or practical level to a more general or conceptual level; changing the focus of a discourse to render it more resonant with the audience or to gain entry into a debate (environmentalists in Canada, for example, rarely use moral arguments when talking to the politicians preferring instead to emphasize practical benefits of adopting their discourse); aligning their discourse with already legitimized institutional discourses. 
What all these have in common that they can be easily illustrated in term of systems theory. In the next section I will look at how Irish Land War meanings of "confiscation" and rent can be seen through systems theory lens.

\section{Restructuring meanings: Rent and Confiscation}

The success of social movements - and indeed any cultural change - must involve the transformation of key dominant meanings by the challenger or challengers. In systems theory terms, this means loosening the dominant system's 'hold' on the public sphere resulting in the restructuring of power relations in the whole system.

A good historical example of this is how the work of mid-eighteenth century French and English thinkers (the philosophes) - including Jean-Jacques Rousseau, Voltaire, David Hume, Adam Smith - loosened the monarchy's hold on the 'public sphere' meanings and replaced the absolute authority of monarchy and its institutions with a system of cultural meanings at the center of which were the ideals of reason, progress, tolerance and limiting the powers of the state. It has been argued - mostly by Marxist cultural philosophers (Hunt 1989:293) - that it is this conceptual reinterpretation (or systemic equilibrium shift) of the role of monarch in the state that eventually led to the French Revolution.

Similar meaning shift (on a much smaller scale, of course) occurred during the Irish Land Wars. In her analysis, Kane shows how the concepts of confiscation and rent were appropriated by the newly-emerged - and constantly negotiated - movement. In the example, the dominant cultural meanings of the words "confiscation" and "rent" were changed (or rather appropriated) by the movement leaders, revealing both the polarized inter-movement priorities (symbolized, in the case of the concept of "confiscation", by 
the discourses of conciliation or retribution), and (in the case of "rent") the movement's ability to both successfully negotiate its own meanings and mobilize against the dominant discourse.

I would now like to show how these two shifts can be conceptualized by systems theory.

\section{Confiscation}

"The land of Ireland has been three times confiscated, but always in favour of the aristocracy. We want a fourth confiscation, or rather a restitution now in favour of the people," (Limerick Reporter, 1879, in Kane 1997:268)

This statement, characteristic of the more radical leaders of the movement (in this case an article by a Limerick lawyer), is an example of how the original cultural meaning of confiscation - "historical wrongs and present injustice and suffering" - was being appropriated by Irish radicals to represent "fair compensation, a just component of righteous retribution."

On the opposing side of the movement, however - on the conciliatory discourse side - the farmers saw themselves not as desperate revolutionaries, but as citizens in need of additional protection from the government. The following excerpt from Dundalk Democrat (1897; in Kane 1997:268) is typical of this more moderate discourse:

"The farmers of Ireland ... should cry out against the terrible injustices to which they are exposed, and demand from the government protection for themselves and properties. The farmers are as peaceable and law-abiding subjects as those who have more power to oppress and rob them."

The above quotation shows the importance of the symbolic structures within which the meaning is being interpreted, but more importantly it shows that meaning can only be accessed through understanding the symbolic structures within which it is being 
interpreted. In the first case, the symbolic interpretative "retribution frame" was mostly embodied by poor farmers with very little to loose and much to gain; the second "conciliatory" frame was embodied mostly by better off farmers and clergy, for both of which the British rule was as much a source of oppression as it was a source of order.

The figure below shows how a systems theory mechanism for the fact movements (which are both multivocal - that is to say speak with many voices - and cohesive) could be conceptualized.

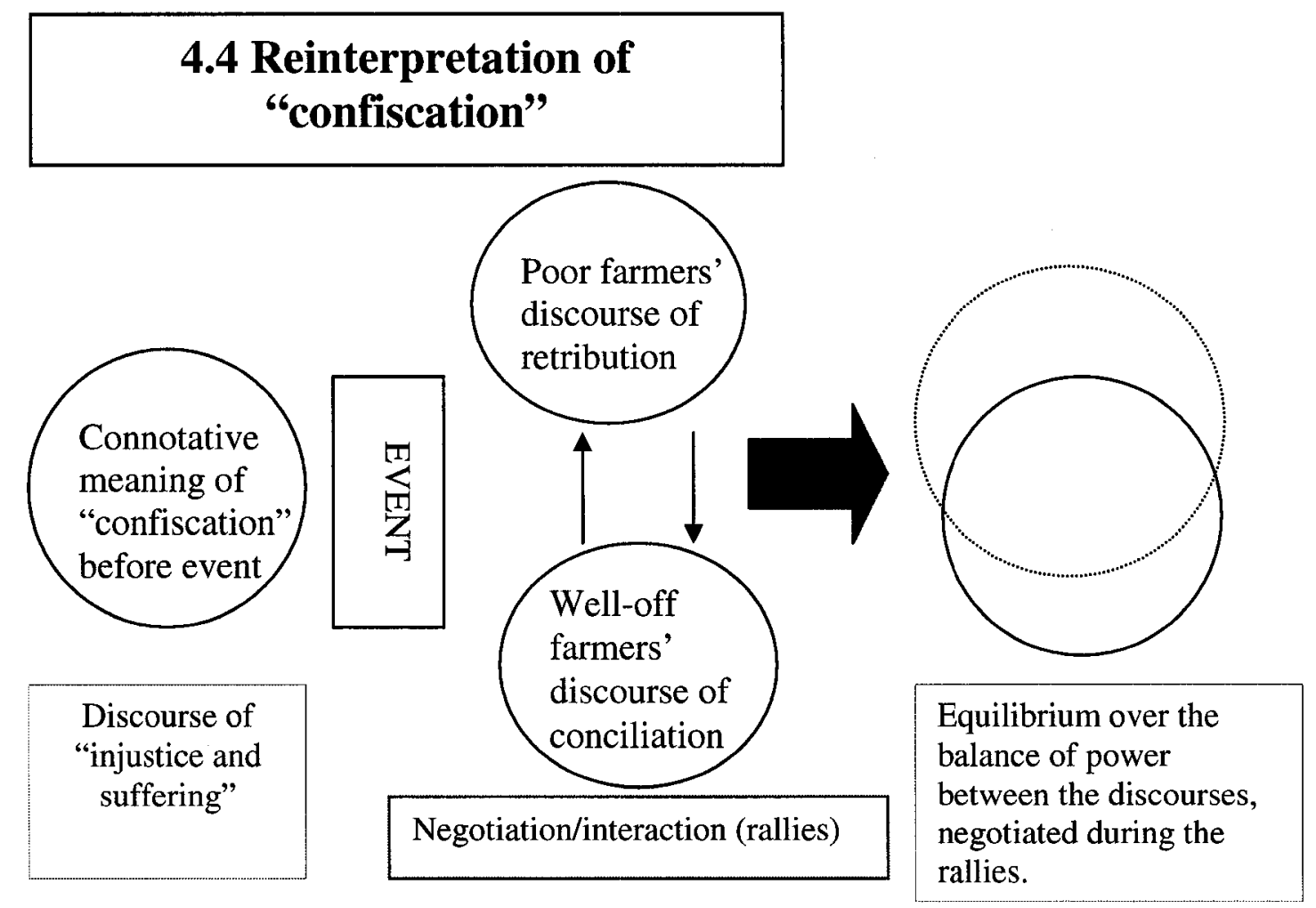

FIGURE 4.2: The change in the meaning of "confiscation" as seen through a systems theory lens.

$\underline{\text { Rent }}$

"It was not until the Land War that rent came to symbolize both tenant and Irish degradation and the evil of landlordism and British domination," says Kane (1997:268). Indeed, while the above figure is an example of how the two different movement 
discourses appropriated the old cultural meanings in different ways, the example below shows how the concept of "rent" was appropriated by the movement more generally and indeed came to be a symbol of resistance.

The following passage by the radical nationalist Michael O'Sullivan (in Kane 1995:269), illustrated how the shift in the meaning of rent - from a status quo that originated from lawful property rights to foreign conquest of Irish lands and oppression of the people - was made possible by actual narratives.

"If, then, the landlords who are now demanding exorbitant rents do not lower them to meet the requirements of the times and the alerted circumstances of the tenant farmers, let the tenant farmers themselves meet together, and consult together, and settle among themselves what should be fair, equitable rent, and if that is not accepted by the landlord - why, let them pay none at all."

The symbolic appropriation of "rent" had a number of consequences in terms of the farmers' own symbolic understanding their situation and obligation to the landlords. Refusing to pay rent not only became a symbol of resistance to the injustices of the system but "fortified and mobilized by these new understandings, Irish tenant farmers came to feel morally justified in not paying rents." And in fact, according to Kane, during the Land War many tenant farmers refused to pay rent and resisted evictions, which often led to violent clashes with the authorities.

Seen in this way, the concept of "rent" after the movement mobilization served as both a constitutive element of the movement identity (against which other elements would position themselves) and as its outcome. The figure below illustrates this. 


\subsection{Reinterpretation of "rent"}

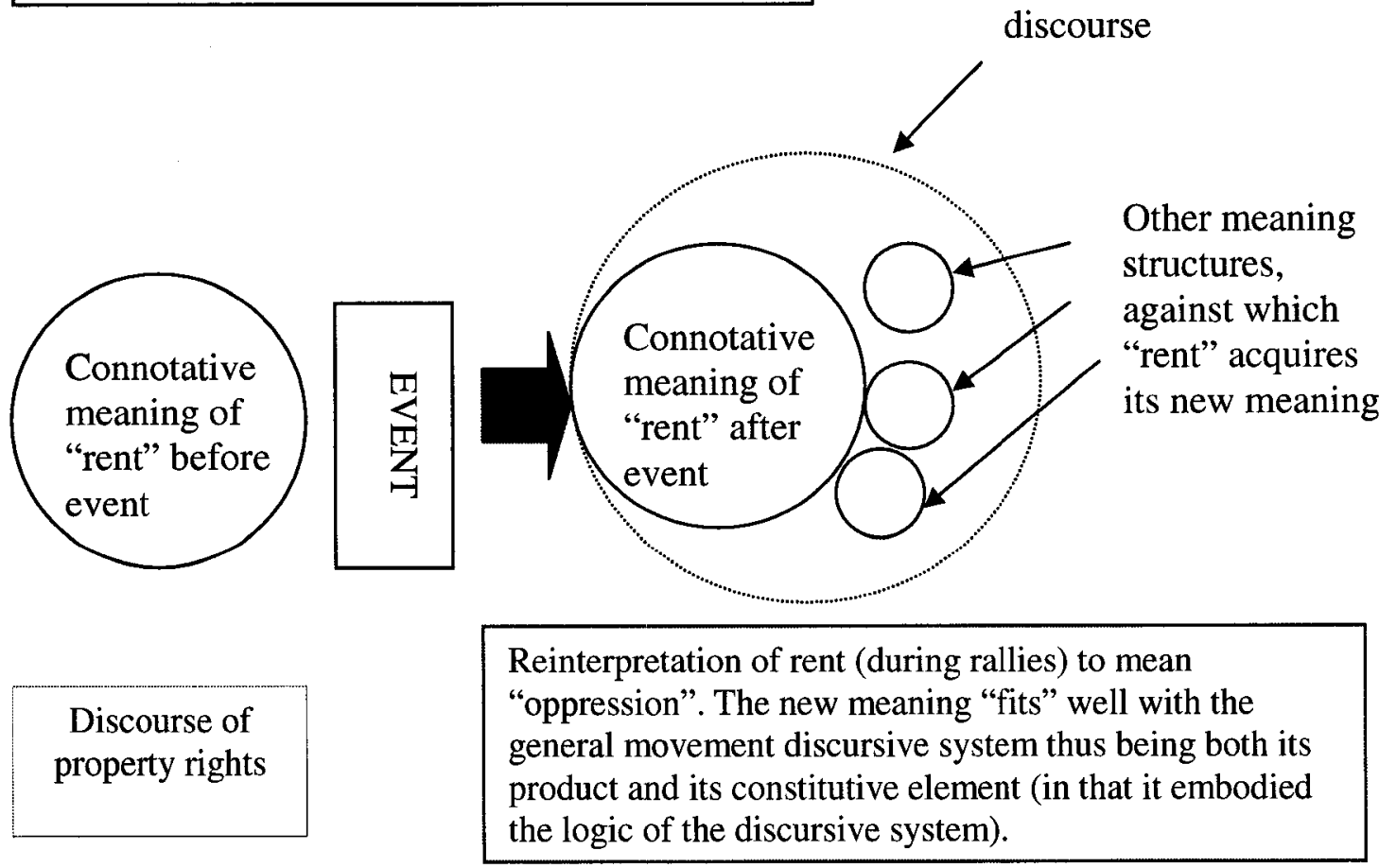

Figure 4.3: The change in the meaning of "rent" as seen through a systems theory lens. 


\subsection{Conclusion}

In this section I tried to compose a systems theory model that was both accommodating of the Irish Land War meaning change and relevant across situations. I argued that it was important for the model to incorporate the three post-frame theory insights of the dialogic school: the symbolic fusion of meaning - which not only accounts for changes in how meaning is negotiated, but also answers why; the structures of the discursive field - which provide us with a theoretical scaffold within which to work; and the dialectical nature of the processes - which brings to our attention the previously underappreciated fact that meaning creation and negotiation is a dynamic phenomenon, in which the processes and structures of communication are so intertwined that a change to one necessitates a change to the other.

I feel all this is clearly illustrated in the case study and the accompanying diagrams, in which I've shown how the organization of a unified discursive system for farmers, unions and clergy has not only changed the vocabularies and discursive power relations in the country, but also the very ways in which farmers used language to describe their place in the world.

The Irish Land War example is an example not only of the fact that symbolic meaning structures in culture serve as templates for interpretation, but also that the construction and transformation of meaning can be understood through the examination of the internal logic of symbolic systems. In other words, in social systems culture plays a causal role, which is to say that rather than being an outcome of political and economic processes, it can drive them. 
This example is also interesting because it allows us to account for both the unpredictability of the process of meaning-making and the causal links between meaning and action. This is to say that contrary to what frame theory would have us believe, meaning is not causal because of the stability of symbolic structures, but it is causal because the fluidity of symbolic systems - which are in nature mutable and transferable allows it to impose "new forms of action and contingent, unforeseen outcomes," (Kane 1997:270) and restructure the dominant social structures.

I have also argued that the analytical lens of dialogic systems theory analysis allows us a deeper understanding of the process of making meaning than is possible using either of the two approaches (dialogic or systems theory) alone. So for one, this hybrid approach allows us to get at the nuances of negotiations within the land movement itself. In the case of the Land War, the voices of poor farmers, the clergy, the union leaders and the well-off farmers, despite being very different, formed a unified front against the common oppressor.

At the same time, however, because the challengers' discursive system was made up of such varied narratives, it fell apart (in that the movement voices again became separate) almost immediately after defeating the dominant discourse (or rather forcing it to allow the Irish more of a voice in the public affairs of the state). Dialogic analysis' insistence on the fact that there is a multitude of discourses/interests within any one discursive system allows us to account for this phenomenon quite well.

More than that however, whereas predicting this occurrence would be completely out of the scope of framing analysis (which does not recognize the multivoicedness of every discourse), within the dialogic systems analysis framework - because of its 
recognition that systems are always created in relation to other systems and that the coalescence among systems is a matter of degree - it would very much be one of the options.

Another advantage of this kind of systems dialogic analysis was made clear the analysis of how language meanings changed to accommodate the new reality of the land movement and vice versa - the rise of the land movement resulted in the movement's appropriation of public language. More than that, however, through this systems semiotic analysis one could show (and this is outside the scope of this paper) just how the new discursive meanings were composed of the parts of the old meanings yet bound by their new context (the environment) as well. 


\section{Future research}

Predicting the behaviour of self-organizing complex systems is very difficult. Indeed, because of the emergent nature of meaning, it is likely that we will never be able to completely predict the behaviour of cultural self-organizing systems. However, as I point out in the introduction, this way (dialogic-systems) of approaching the problem of meaning has a number of advantages over the more analytical, quantitative methods (discourse analysis), which while capable of providing the numbers are not able to give us real insight into how qualitatively different phenomena are organized on multiple levels.

It also has the advantage of having incorporated structuralist and poststructuralist insights. This is to say that it acknowledges - and tries to account for in the models - a complex relationship between the structures of meaning and the practices that embody and indeed give rise to these structures. In other words, it attempts to bridge the chasm between the two schools of thought that dominate theorising about culture and meaning: one which sees culture as instances of meaning enactment and one which sees culture as embedded in the interaction between social structures.

Already, many researchers - a good number of them mentioned in the paper - use the ideas discussed here to look at particular instances of meaning negotiation. Their efforts range from attempting to unravel social communications in general (Fuchs 2006) to studying cultural changes (Kane, Steinberg, Ellingson) to theorizing about organizational behaviour (Hawes 1999).

There are many possibilities here for future research. They range from developing better bridges among systems - which is to say propose better ways in which discursive 
artefacts (e.g. narratives) interact - to simply describing each system of meanings on its own (by outlining the logic of its meaning-making). At this point in research, the latter would appear to be a more realistic goal. Indeed, researchers often focus more on trying to describe the criteria that any future theory in this field must meet rather than on developing an actual theory.

As an example, Van de Ven \& Poole and Poole (1988), in their analysis of theory of organizational change, formulate a number of "paradoxical requirements" that any worthwhile dialogic theory must address. These include (1) action-structure paradox; (2) internal and external sources of change; (3) stability and change; and (4) time - macro and micro history. Poonamallee (2006:262) added two more criteria to the list: (5) ability to account for both outcome and change, and (6) accounting for the cooperation and conflict.

In this paper I have tried to show that the line of theorising I proposed, i.e., the lens of the dialogic-systems theory, is one way of meeting these requirements - thus creating a nuanced theory of meaning construction and change. Future work may focus on refining or further integrating these general theoretical requirements in a dialogicsystems tradition by examining instances of meaning changes and describing the mechanisms of symbolic change based on the results of an empirical inquiry. 


\section{Bibliography}

Bakhtin, M. 1981. The Dialogic Imagination: Four Essays, Michael Holquist (trans.) Caryl Emerson and Michael Holquist (eds.). Austin: University of Texas Press.

Bakhtin, M. 1986. Speech Genres and Other Late Essays. Vern W. McGee (trans.) University of Texas Press.

Bakthtin, M. 1993. Toward a Philosophy of the Act. Vadim Liapunov and Michael Holquist (eds). Liapunov (trans.). University of Texas Press.

Bateson, Gregory. 1991. A Sacred Unity: Further Steps to an Ecology of Mind. HarperCollinsPublishers.

Battani, M., Hall, D., and Powers, R. 1997. "Cultures' structures: Meaning making in the public sphere," Theory and Society, 26, 781-812.

Baudrillard, J. 1991. “The Gulf War Did Not Take Place.” Liberation, March 29.

Boje, D.M., Al Arkoubi, K. 2005. "Toward a dialogic system theory," paper presented to 16th Annual Meeting of Standing Conference for Management and Organization Inquiry, April 8/9. Available at: http://scmoi.org.

Chandler, D. 1999. Semiotics for Beginners. From:

http://www.aber.ac.uk/media/Documents/S4B/semiotic.html

Contractor, N. 1999. "Self-organizing systems research in the social sciences:

Reconciling the Metaphors and the Models," Management Communication Quarterly, Vol. 13, No. 1. 154-166.

Cook, D. J. 1982. "Marx's Critique of Philosophical Language." Philosophy and Phenomenological Research, 42, no. 4: 530-54.

Croning, P. 2002. "The Re-Emergence of Emergence: A Venerable Concept in Search of a Theory." From http://www.complexsystems.org/publications/pdf/emergence3.pdf

Dale, S. 1996. McLuhan's Children: the Greenpeace Message and the Media. Between the Lines, Toronto.

De Rosnay, J. 1979. The macroscope: a new world scientific system. Robert Edwards (trans.). Harper and Row, New York, New York, USA.

Derrida, J. 1981. Positions. Chicago \& London: University of Chicago Press.

Echo, U. 1986. Semiotics and the Philosophy of Language. Indiana University Press. 
Ellingson, S. 1995. "Understanding the Dialectic of Discourse and Collective Action: Public Debate and Rioting in Antebellum Cincinnati," American Journal of Sociology, 101 (no. 1, July), 100-44.

Foucault, M. 1988. Madness and Civilization: A History of Insanity in the Age of Reason. Vintage Press.

Fuchs, C. "The self-organization of the cultural subsystem of modern society," Contribution to the $12^{\text {th }}$ Fuschl Conversations: New Agoras for the $21^{\text {st }}$ Century: Conscious Self-Guided Evolution, April 18-23, 2004.

Available at: http://cartoon.iguw.tuwien.ac.at/christian/culture.pdf

Fuchs, C. 2006. “The Self-Organization of Social Movements," Systemic Practice and Action Research, Vol. 19, No. 1.

Geertz, C. 1973. The Interpretation of Cultures: Selected Essays. Basic Books. New York.

Gershenson, C. and F. Heylighen. 2003. "When Can we Call a System Self-organizing?" In Banzhaf, W, T. Christaller, P. Dittrich, J. T. Kim, and J. Ziegler, Advances in Artificial Life, $7^{\text {th }}$ European Conference, ECAL 2003, Dortmund, Germany, pp. 606-614. Available at: http://uk.arxiv.org/ftp/nlin/papers/0303/0303020.pdf

Giddens, A. 1979. Central Problems in Social Theory. London: Macmillan.

Goldstein, J. 1999. "Emergence as a Construct: History and Issues", Emergence: Complexity and Organization, 1: 49-72.

Goffman, E. 1959. Presentation of Self in Everyday Life. New York: Doubleday.

Goffman, E. 1974. Frame Analysis. Cambridge: Harvard University Press.

Hawes, L. 1999. "Dialogics, Posthumanist Theory, and Self-Organizing Systems," Management Communication Quarterly, Vol. 13, No.1, 146-153.

Holdcroft, D. 1991. Saussure: Signs, System, and Arbitrariness. Cambridge: Cambridge University Press.

Holmwood, J. 2005. "Functionalism and its Critics" in Harrington, A., (ed.) Modern Social Theory: An introduction, Oxford University Press, Oxford, pp. 87-109.

Jasper, J. M. 1997. The Art of Moral Protest. Chicago: University of Chicago Press. Johnson-Cartee, K. 2005. News narrative and news framing: Constructing political reality. Lanham, MD: Rowman and Littlefield. 
Kane, A.E. 1997. "Theorizing Meaning Construction in Social Movements: Symbolic Structures and Interpretation during the Irish Land War, 1879-1882," Sociological Theory, $15,249-76$.

Kane, A.E. 2000. "Reconstructing Culture in Historical Explanation: Narratives as Cultural Structure and Practice," History and Theory, 39, 311-30.

Konig, T. 2007. "Frame Analysis: A Primer." Available at: http://www.lboro.ac.uk/research/mmethods/resources/links/frames_primer.html

Lemke, J.L. 1999. "Opening Up Closure: Semiotics Across Scales." Available at: http://www-personal.umich.edu/ jaylemke/papers/gent.htm

Lemke, J.L. 1995. Textual Politics: Discourse and Social Dynamics. Taylor and Francis Publishing.

Lemke, J.L. 1994. "Discourse, Dynamics, and Social Change." Cultural Dynamics 6(1): 243-275.

Lemke, J. L. 1994. "Downward Causation, Material Sign Process and Emergent Ecosocial Organization.” Revised chapter for P.B. Andersen et al. (eds.).

Available at: http://academic.brooklyn.cuny.edu/education/jlemke/aarhus.htm

Locke, J. 1963. The Works of John Locke, A New Edition. Vol. III. T. Tegg, London.

Hunt, L. 1989. "Introduction: The French Revolution in Culture: New Approaches and Perspectives, Eighteenth-Century Studies," Vol. 22, No. 3, Special Issue: The French Revolution in Culture, pp. 293-301.

Maturana, H. and Varela, F. 1980. "Autopoiesis and Cognition: the Realization of the Living." Robert S. Cohen and Marx W. Wartofsky (eds.), Boston Studies in the Philosophy of Science, 42. Dordecht: D. Reidel Publishing Co.

Merton, R. 1968. Social Theory and Social Structure. The Free Press: New York.

McAdam, D., McCarthy, J., \& Zald, M. (1996). "Introduction: Opportunities, Mobilizing Structures, and Framing Processes-Toward a Synthetic, Comparative Perspective on Social Movements." In D. McAdam, J. McCarthy and M. Zald (eds.), Comparative Perspectives on Social Movements. New York: Cambridge University Press.

Montuori, A., Purser, R. 1996. "Ecological futures: Systems theory, postmodernism, and participative learning in an age of uncertainty." In D. Boje, D. Gephart and T. Joseph, (Ed.). Postmodernism and Organization Theory, pp.181-201 Newbury Park: Sage. Available at: http://ciis.edu/faculty/articles/montuori/ecologicalfutures.pdf 
Nelson, T. E., Oxley, Z. M. and Clawson, R. A. 1997. "Toward a psychology of framing effects." Political Behavior, 19 (3), 221-246.

Oliver, P E. and H. Johnston. 2000. "What a Good Idea: Frames and Ideologies in Social Movements Research." Mobilization, 5 (1): 37-54.

Pan. Z. \& Kosicki, G. M. 2001. "Framing as a strategic action in public deliberation." In S. D. Reese, O. H. Gandy, Jr., and A. E. Grant (eds.), Framing public life: Perspectives on media and our understanding of the social world, 35-66. Mahwah, NJ: Lawrence Erlbaum Associates.

Peirce, Ch. 1998. The Essential Perice: Selected Philosphical Writings, 1893-1913. Nathan Hourser and Jonathan Eller (eds.). Indiana University Press.

Peters, J.D. "John Locke, the Individual, and the Origin of Communication." Quarterly Journal of Speech 75, no. 4: 387-99.

Poonamallee, L. 2006. "From Dialectic to Dialogic: Generative Organizing for Social Transformation - A comparative Case Study in India." Available at: http://www.ohiolink.edu/etd/send-pdf.cgi/Poonamallee\%20Latha.pdf?case1145044613

Principia Cybernetica Web. Heylighen, F, Joslyn, C. and V. Turchin (eds.) Available at: http://pespmc1.vub.ac.be/ANALSYST.html

Salathe, S. 1993. Development and Evolution: Complexity and Change in Biology. MIT Press.

Shaviro, Steven. 1986. "From Language to 'Forms of Life': Theory and Practice in Wittgenstein." Social Text, no. 13/14: 216-36.

Steinberg, M. W. 1999. "The Talk and Back Talk of Collective Action: A Dialogic Analysis of Repertoires of Discourse among Nineteenth-Century English Cotton Spinners." American Journal of Sociology, 105, 736-80.

Snow, D. A., and Benford, R. D. 1988. "Ideology, frame resonance, and participant mobilization." International Social Movement Research, 1, 197-217.

Snow, D. A., Rochford, E. B., Worden, S. K., and Benford, R. D. 1986. "Frame alignment processes, micromobilization, and movement participation." American Sociological Review, 51, 464-481.

Rorty, R. 1989. Contingency, Irony and Solidarity. Cambridge: Cambridge University Press. "Ch. 6: From ironist theory to private allusions: Derrida."

Van de Ven and Poole. 1988. "Alternative Approaches for Studying Organizational Change." Organization Studies, 26, 1377-1404. Available at: 
http://webpages.csom.umn.edu/smo/avandeven/ProcessResearch/VandeVen\&Poole05.pd f

Varela, F. J.; Maturana, H R. and Uribe, R. 1974. "Autopoiesis: the organization of living systems, its characterization and a model." Biosystems, 5 187-196.

Wilden, A. 1987. The Rules Are No Game: The Strategy of Communication. London: Routledge and Kegan Paul.

Whelan, F.G. 1981. "Language and Its Abuses in Hobbes' Political Philosophy." American Political Science Review 75, no. 1, 59-75.

Yazdanpour, E. 1998. "From Idea of Novel to Novel of Ideas: A Survey of the Ideas of Bakhtin." Available at: http://www.geocities.com/yazdanpour/y-thesis.htm. 